\title{
Src Kinase Is Biphosphorylated at Y416/Y527 and Activates the CUB-Domain Containing Protein $1 /$ Protein Kinase $C \delta$ Pathway in a Subset of Triple-Negative Breast Cancers
}

Luke J. Nelson, ${ }^{*}$ Heather J. Wright, ${ }^{*}$ Nguyen B. Dinh, ${ }^{*}$ Kevin D. Nguyen, ${ }^{*}$ Olga V. Razorenova, ${ }^{*}$ and F. Scott Heinemann

From the Department of Molecular Biology and Biochemistry, ${ }^{*}$ University of California, Irvine, Irvine; and the Department of Pathology, ${ }^{\dagger}$ Hoag Memorial Hospital Presbyterian, Newport Beach, California

Accepted for publication October 15, 2019.

Address correspondence to F. Scott Heinemann, M.D., Department of Pathology, Hoag Memorial Hospital, One Hoag Dr., Newport Beach, CA 92663; or Olga V. Razorenova, $\mathrm{Ph} . D$., University of California, Irvine, 845 Health Sciences Rd., Gross Hall - Room 3010, Mail Code 3900, Irvine, CA 92697. E-mail: fscott. heinemann@hoag.org or olgar@uci.edu.

\begin{abstract}
Targeted therapeutics are needed for triple-negative breast cancer (TNBC). In this study, we investigated the activation of Src family of cytoplasmic tyrosine kinases (SFKs) and two SFK substrates-CUB-domain containing protein 1 (CDCP1) and protein kinase $C \delta(P K C \delta)$-in 56 formalin-fixed, paraffin-embedded (FFPE) TNBCs. Expression of SFK phosphorylated at Y416 (SFK_pY416 ${ }^{+}$) in tumor cells was strongly associated with phosphorylation of CDCP1 and PKC $\delta\left(C D C P 1 \_p Y 743^{+}\right.$and $P K C \delta \_p Y 311^{+}$), as assessed by immunohistochemistry, indicating increased SFK activity in situ. To enable biochemical analysis, protein extraction from FFPE tissue was optimized. Cleaved CDCP1 isoform (70 kDa) was expressed to a varying degree in all samples but only phosphorylated in TNBC tumor cells that expressed SFK_pY416. Interestingly, active SFK was found to be biphosphorylated (SFK_pY $416^{+} / \mathrm{pY} 527^{+}$). Biphosphorylated active SFK was observed more frequently in forkhead box protein A1 (FOXA1)- TNBCs. In addition, in SFK_pY416 ${ }^{-}$samples, FOXA1 ${ }^{+}$TNBC tended to be SFK_pY527 ${ }^{+}$(classic inactive SFK), and FOXA1 ${ }^{-}$TNBC tended to be SFK_pY527 ${ }^{-}$ (SFK poised for activation). Strong SFK_pY416 staining was also observed in tumor-infiltrating lymphocytes in a subset of TNBCs with high tumor-infiltrating lymphocyte content. This report will facilitate protein biochemical analysis of FFPE tumor samples and justifies the development of therapies targeting the SFK/ CDCP1/PKC $\delta$ pathway for TNBC treatment. (Am J Pathol 2020, 190: 484-502; https://doi.org/ 10.1016/j.ajpath.2019.10.017)
\end{abstract}

Triple-negative breast cancer (TNBC) is a heterogeneous group of malignant neoplasms defined by the absence of estrogen receptor, human epidermal growth factor 2 receptor, and progesterone receptor. ${ }^{1,2}$ Because TNBCs are frequently aggressive and are defined by a lack of known therapeutic targets, effort has been made toward understanding the biology of TNBC. Gene expression analysis initially identified a subgroup of TNBCs with an androgen receptor (AR)-driven expression profile. ${ }^{3,4}$ More important, AR-driven transcription is mediated by forkhead box protein A1 (FOXA1), the master regulator of steroid receptor function in cancer. ${ }^{5,6}$ Since then, gene expression analysis and integrated genomic/gene expression analyses have consistently identified three main types of TNBC: luminal AR (LAR), basal-like (BL), and mesenchymal. ${ }^{7-10}$
Moreover, several independent gene expression analyses have identified a subset of BL-TNBC with an activated immune gene expression signature. ${ }^{8,9,11}$ The role of immune activation in LAR and mesenchymal TNBC is not well defined. Despite progress in understanding the biological heterogeneity of TNBC, there remains a clear need for development of new targeted molecular therapies and

Supported by NIH grant UL1 TR001414 (L.N.); Concern Foundation grant CF-204722 (O.V.R.); University of California,Irvine grant UCCRCC103723 (O.V.R.); National Cancer Institute grant F31CA196226 (H.J.W.); and Hoag Hospital Research Funds (F.S.H.).

Disclosures: None declared.

Current address of H.J.W., Fred Hutchinson Cancer Research Center, Seattle, WA; of K.D.N., Saint Louis University School of Medicine, St. Louis, MO. 
companion biomarkers for each subtype of these aggressive neoplasms.

Activation of Src kinase, the first identified protein tyrosine kinase ${ }^{12}$ and founding member of the Src family of cytoplasmic tyrosine kinases (SFKs), has been implicated in the progression of multiple solid tumors, including breast cancer. $^{13-18}$ Increased SFK activity was identified in breast cancer tissue relative to normal breast tissue, particularly in high-grade cancers. ${ }^{19}$ Early studies concluded that increased SFK activity in solid tumors was the result of increased specific activity and/or increased expression of the Src isoform of SFK..$^{20-23}$ Recently, several studies have suggested that other SFK isoforms, particularly leukocyte C-terminal Src kinase (Lck) and Lck/yes-related novel protein tyrosine kinase (Lyn), are highly expressed in breast cancer and play a significant role in TNBC. ${ }^{24-26}$ The results of large-scale genomic sequencing projects indicate that gene amplification and activating mutations in SFK do not play a significant role in human tumor biology. ${ }^{27-29}$ This suggests that activation of SFK in human cancers results from dysregulation of allosteric activation mechanisms and/or dysregulated expression.

Similar to most protein kinases, SFK activity is tightly regulated by phosphorylation of several key residues. ${ }^{30,31}$ SFKs are negatively regulated via phosphorylation by $\mathrm{C}$ terminal Src kinase at a conserved C-terminal tyrosine (Y527 in chicken Src and Y530 in human Src; the chicken protein sequence numbering is commonly used in literature and in this article). Phosphorylation of Y527 stabilizes an inactive SFK conformation through an intramolecular interaction between phosphorylated Y527 and the Src homology domain 2 in SFK that lies on the N-terminus side of the kinase domain. Dephosphorylation at Y527 is the first step in the canonical pathway of SFK activation. ${ }^{32}$ Full activation of SFK requires phosphorylation of Y416 in the activation loop, which locks the catalytic domain in an active conformation. ${ }^{33}$ Phosphorylation of SFK at Y416 is known to occur in the context of dimerized and activated receptor tyrosine kinases and $a \beta$-integrin complexes and likely primarily occurs by transautophosphorylation. ${ }^{34-36}$ Activated SFKs control a host of cellular functions, including proliferation, differentiation, and cell migration/ invasion, through multiple downstream effectors. ${ }^{35,37}$

CUB-domain containing protein 1 (CDCP1) is a transmembrane glycoprotein that is both an SFK substrate ${ }^{38,39}$ and an SFK activator. CDCP1 also acts as an SFK signaling regulator, directing phosphorylation of specific SFK substrates, including protein kinase C $\delta$ (PKC $\delta) .{ }^{40,41}$ CDCP1 is expressed in embryonic stem cells and many cancer cell types. ${ }^{42}$ CDCP1 is highly expressed and activated in TNBC, ${ }^{43,44}$ driving tumor progression and metastasis in animal models. CDCP1 can be expressed at the cell membrane as a full-length approximately 140-kDa form and/or a cleaved approximately 70 - to $80-\mathrm{kDa}$ form. ${ }^{45}$ The protumorigenic effects of CDCP1 depend on co-expression of SFK, which is capable of phosphorylating CDCP1 at multiple cytoplasmic tyrosine residues. ${ }^{38,40,46,47}$ Accordingly, in this pathway of oncogenic SFK signaling, SFK phosphorylation of CDCP1 at Y734 generates a highaffinity binding site for the Src homology domain 2 of SFK, ${ }^{41,45}$ which is critical for SFK phosphorylation of CDCP1 at other residues (including Y743) and for CDCP1 downstream signaling. ${ }^{38,40}$ PKC $\delta$ binding to CDCP1 stimulates $\mathrm{PKC} \delta$ phosphorylation at $\mathrm{Y} 311$ by $\mathrm{SFK}^{41,48}$ and increases cell migration and invasion. ${ }^{49} \mathrm{PKC} \delta$ signaling has been implicated in several types of cancer and appears to have a role in both regulation of cell proliferation and apoptosis, as well as the migratory behavior of cancer cells. $^{49-52}$ The role of $\mathrm{PKC} \delta$ in TNBC pathogenesis remains unclear. Nevertheless, the SFK/CDCP1/PKC $\delta$ signaling pathway appears to be clinically relevant because CDCP1 tyrosine phosphorylation has been correlated with the phosphorylation of SFKs and PKC $\delta$ in non-small-cell lung cell tumor samples ${ }^{53}$ and breast tumor samples. ${ }^{46}$ Although the SFK/CDCP1/PKC $\delta$ pathway was shown to be active in TNBC cell lines and cell line-based animal models, there is a lack of studies directly analyzing this signaling pathway in a cohort of TNBC patient samples.

Analysis of an integrated $\mathrm{mRNA} /$ protein database indicated that phosphorylation of SFKs at Y416 (SFK_pY416 ${ }^{+}$) is associated with an active immune response in TNBC. To study SFK/CDCP1/PKC $\delta$ signaling in TNBC and its possible connection to immune activation, we evaluated the expression of phosphorylated isoforms of SFK, CDCP1, and PKC $\delta$ by immunohistochemistry (IHC). These proteins were then examined by Western blot analysis after optimizing a method to extract protein from formalin-fixed, paraffin-embedded (FFPE) tissue samples. Western blot analyses confirmed IHC observations and allowed analysis of expression of several phosphoproteins that were not detected by IHC. Immunoprecipitation (IP) of solubilized FFPE tissue allowed characterization of the phosphorylation pattern of SFK isoforms in histologically distinct tumors. Our results reveal a pattern of SFK, CDCP1, and PKC $\delta$ phosphorylation that suggests biphosphorylated (pY416 ${ }^{+} /$ pY $527^{+}$) SFK is expressed in TNBC and is active in signal transduction to CDCP1 and PKC $\delta$ in a subset of TNBCs. In addition, we report on SFK activation in tumor-infiltrating lymphocytes of TNBC and its association with expression of immune checkpoint proteins cytotoxic T-lymphocyte protein 4 (CTLA4), programmed cell death protein 1 (PD1), and programmed cell death 1 ligand 1 (PD-L1).

\section{Materials and Methods}

\section{Selection and Preparation of Tumor Punch Biopsy Samples}

Archival triple-negative breast cancer resections were identified by review of pathology records at Hoag Memorial Hospital Presbyterian (Newport Beach, CA). Tumors that were reported to be estrogen receptor/progesterone receptor/ 
Table 1 Antibodies and Dilutions Used for IHC and Western Blot Analysis

\begin{tabular}{|c|c|c|c|c|}
\hline Antigen & Antibody information, manufacturer/catalog no. & Western blot dilution & IHC dilution & Antigen retrieval* \\
\hline F0XA1 & Abcam/ab173287 & NA & $1: 4000$ & 1 \\
\hline Vimentin & Agilent/M0725 & NA & $1: 2000$ & 2 \\
\hline Sox10 & Bio SB/BSB2583 & NA & 1:100 & 1 \\
\hline CK5/6 & Thermo Fisher Scientific/180267 & NA & $1: 50$ & 2 \\
\hline CDCP1 & Cell Signaling Technology/4115 & $1: 1000$ & $1: 100$ & 1 \\
\hline CDCP1_pY743 & Cell Signaling Technology/14965 & $1: 1000$ & $1: 800$ & 1 \\
\hline CDCP1_pY734 & Cell Signaling Technology/9050 & 1:1000 & NA & NA \\
\hline Src & Cell Signaling Technology/2108 & 1:1000 & NA & NA \\
\hline Lck & Cell Signaling Technology/2752 & $1: 1000$ & NA & NA \\
\hline Lyn & Cell Signaling Technology/2732 & $1: 1000$ & NA & NA \\
\hline SFK_pY416 & Cell Signaling Technology/2101 & $1: 1000$ & $1: 200$ & 1 \\
\hline SFK_pY527 & Cell Signaling Technology/2105 & $1: 1000$ & NA & NA \\
\hline $\mathrm{PKC} \delta$ & Cell Signaling Technology/2058 & $1: 1000$ & NA & NA \\
\hline PKC $\delta \_p Y 311$ & Abcam/ab76181 & $1: 2500$ & $1: 3000$ & 1 \\
\hline $\mathrm{N}$-cadherin & Cell Signaling Technology/13116 & NA & $1: 200$ & 1 \\
\hline Slug & Cell Signaling Technology/9585 & NA & $1: 100$ & 1 \\
\hline AMPK $\alpha$ & Cell Signaling Technology/2532 & $1: 1000$ & NA & NA \\
\hline AMPK $\alpha \_p T 172$ & Cell Signaling Technology/2535 & 1:1000 & NA & NA \\
\hline$\beta$-Actin & Leica Biosystems/A5441 & $1: 5000$ & NA & NA \\
\hline CD3 & Novocastra/NCL-L-CD3-565 & NA & $1: 50$ & 2 \\
\hline PD1 & Cell Signaling Technology/86163 & NA & $1: 200$ & 2 \\
\hline PD-L1 & Cell Signaling Technology/13684 & NA & $1: 400$ & 2 \\
\hline CTLA4 & Santa Cruz Biotechnology/sc-376016 & NA & $1: 400$ & 2 \\
\hline
\end{tabular}

*Antigen retrieval 1: heat 20 minutes off-line in Leica ER2 buffer in steamer; repeat online with Leica ER2 buffer for 20 minutes. Antigen retrieval 2: dewax and antigen retrieval online in Leica ER2 buffer for 20 minutes.

AMPK, AMP-activated protein kinase; CDCP, CUB-domain containing protein; CK5/6, cytokeratin 5/6; CTLA4, cytotoxic T-lymphocyte protein 4; F0XA1, forkhead box protein A1; IHC, immunohistochemistry; Lck, tyrosine-protein kinase Lck; Lyn, tyrosine-protein kinase Lyn; NA, not applicable; PD1, programmed cell death protein 1; PD-L1, programmed cell death 1 ligand 1; PKC, protein kinase C; Sox10, Sry-box transcription factor 10.

human epidermal growth factor 2 receptor negative, according to American Society of Clinical Oncology-College of American Pathologists guidelines, were considered TNBC. Case slides were selected for review on the basis of availability of slides and blocks, adequate tumor size $(>15$ $\mathrm{mm}$ ), and a histologic diagnosis of invasive ductal carcinoma. TNBCs of special types, including lobular carcinoma and low-grade metaplastic carcinoma, were excluded. Highgrade metaplastic carcinomas were included. Tumors from patients who had received neoadjuvant chemotherapy were included in the slide review, but tumors with morphologic evidence of response to neoadjuvant chemotherapy were excluded from further study. A total of 56 TNBCs were selected. Most of the tumors were resected between 2011 and 2016. Five of the 56 tumors selected for study were from patients who had received neoadjuvant chemotherapy (TNBC2, TNBC10, TNBC11, TNBC36, and TNBC41). None of these tumors demonstrated high levels of SFK activation (Supplemental Table S1).

Foci of carcinoma were microdissected from the original paraffin block using a 3- or 4-mm punch biopsy tool and reembedded in a $10 \times 10$-mm paraffin block with a unique identifier. Areas of tumor that contained a high proportion of tumor cells were targeted for microdissection. Tumor-cell rich areas were often located near the tumor-stromal interface, but tumor near the tumor-stromal interface was not targeted per se. Only intratumoral areas were targeted for microdissection, but some foci contained a small amount of peritumoral stroma. Areas of tumor with extensive necrosis or a high percentage of stroma were avoided. Standard clinicopathologic data, including patient age, tumor size, histologic grade, node status, and history of neoadjuvant chemotherapy, were linked to the tumor sample identifier. The study design was reviewed by the Western Institutional Review Board (number 1-890338-1) and determined to pose less than minimal risk to participants and, therefore, exempt from the informed consent requirement.

\section{Reagents and Antibodies}

The following primary antibodies were used: SFK_pY416 number 2101, SFK_pY527 number 2105, Src number 2108, Lyn number 2732, Lck number 2752, CDCP1 pY734 number 9050, CDCP1 pY743 number 14965, CDCP1 number 13794, CDCP1 number 4115, PKC $\delta$ pY311 number 2055, PKC $\delta$ number 2058, AMP-activated protein kinase alpha (AMPK $\alpha$ ) pT172 number 2535, AMPK $\alpha$ number 2532, N-cadherin number 13116, Slug number 9585, PD1 number 86163, and PD-L1 number 13684 (Cell Signaling Technology, Danvers, MA); PKC $\delta$ pY311 number ab76181 and FOXA1 number ab173287 (Abcam, Cambridge, MA); vimentin number MA511883 and 
cytokeratin 5/6 (CK5/6) number 180267 (Thermo Fisher Scientific, Waltham, MA); $\beta$-actin number A5441 (Millipore Sigma, St. Louis, MO); vimentin number M0725 (Agilent, Santa Clara, CA); Sry-box 10 (Sox10) number BSB2583 (Bio SB, Santa Barbara, CA); CD3 number NCLL-CD3-565 (Leica Biosystems, Wetzlar, Germany); and CTLA4 number sc-376016 (Santa Cruz Biotechnology, Dallas, TX). Antibody dilutions for each method are listed in Table 1.

\section{Immunohistochemical Staining}

Immunohistochemical staining was performed on the BOND III automated immunostainer (Leica Biosystems). In brief, sections ( $3 \mu \mathrm{m}$ thick) of microdissected tumor foci were mounted on adhesive slides and baked for 60 minutes at $60^{\circ} \mathrm{C}$. Up to eight tumor foci were evaluated per slide. For phosphoprotein staining, slides were dewaxed and rehydrated manually, and antigen retrieval was performed in a pressure cooker for 20 minutes in Leica epitope retrieval solution 2. When offline antigen retrieval was performed, cover tiles were applied to wet slides, the immunostainer programmed to run with the dewax step was turned off, and a second antigen retrieval step was programmed (Table 1). All slides were stained using a 73-minute protocol that included a 30-minute ambient temperature antibody incubation step, except $\mathrm{CD} 3$, which had a 15-minute antibody incubation. Bound antibody was detected using the Bond Polymer Refine Detection system (Leica Biosystems), and the slides were counterstained with hematoxylin.

\section{Scoring of Immunohistochemical Stains}

SFK_pY416, CDCP1_pY743, and PKCD_pY311

The percentage of tumor cells staining as well as the localization of the stain (membrane, cytoplasm, or nucleus) were recorded. The staining of tumor cells with these antibodies was predominantly membranous. The following criteria were used to score the intensity of staining: strong $\left(3^{+}\right)$, intense circumferential membrane staining; moderate $\left(2^{+}\right)$, moderate circumferential membrane staining; and weak $\left(1^{+}\right)$, weak circumferential membrane staining or weak/moderate staining that is incomplete. The intensity of SFK_pY416 staining in lymphocytes was scored as follows: strong $\left(3^{+}\right)$, intense staining that is visible with $4 \times$ objective; moderate $\left(2^{+}\right)$, moderate staining that is visible with $10 \times$ objective; weak $\left(1^{+}\right)$, staining that can only be appreciated with $40 \times$ objective; and negative (0), no visible staining with $40 \times$ objective. The percentage of lymphocytes with each stain intensity was recorded to calculate a histoscore.

F0XA1, Vimentin, CK5/6, and S0X10

For FOXA1, the percentage of tumor cells with nuclear staining was recorded. Nuclear staining of any intensity was considered positive. For vimentin, the percentage of tumor cells with cytoplasmic and/or nuclear staining was recorded.
Staining of any intensity was considered positive. The percentage of tumor cells with nuclear SOX10 staining or cytoplasmic CK5/6 staining was recorded. Any intensity of staining was considered positive. For all these markers, tumors were recorded as positive if $>1 \%$ of the tumor cells were positive.

\section{CD3, PD1, PD-L1, and CTLA4}

CD3 staining was scored as positive or negative to estimate the number of T cells in a tumor. PD1, PD-L1, and CTLA4 stains were assessed visually to assess the percentage of tumor surface area occupied by cells expressing these antigens and the intensity of staining. The criteria for interpreting the intensity of staining were identical to the criteria used to score the intensity of SFK_pY416 staining in lymphocytes: strong $\left(3^{+}\right)$, intense staining that is visible with $4 \times$ objective; moderate $\left(2^{+}\right)$, moderate staining that is visible with $10 \times$ objective; weak $\left(1^{+}\right)$, staining that can only be appreciated with $40 \times$ objective; and negative (0), no visible staining with $40 \times$ objective.

\section{Weighted Histoscores and Overall Scores for Tumor} SFK_pY416, Lymphocyte SFK_pY416, PD1, PD-L1, and CTLA4 Weighted histoscores and overall scores were determined for five markers in a subset of the tumors $(n=38$ for CTLA4; $n=43$ for the others): the weighted histoscore for each marker was calculated by the formula: $\left(\% 3^{+} \times\right.$ $3)+\left(\% 2^{+} \times 2\right)+\left(\% 1^{+}\right)$.

The overall score for each marker was calculated as the product of the fraction of surface area occupied by cells expressing the marker and the weighted histoscore.

\section{Extraction of Protein and Western Blot Analysis}

Protein extraction from FFPE tissue was performed as follows: sections ( $40 \mu \mathrm{m}$ thick) of FFPE were placed in 2-mL screw cap vials. Paraffin was removed by two washes of xylene. Xylene was removed with two washes of reagent alcohol and one wash of methanol. The deparaffinized tissue was rehydrated in ultrapure water. For Western blot analysis, the rehydrated tissue sections were suspended in 50 volumes of extraction buffer (4\% SDS, $125 \mathrm{mmol} / \mathrm{L}$ Tris$\mathrm{HCl}, 100 \mathrm{mmol} / \mathrm{L}$ dithiothreitol (DTT), and 20\% glycerol) and placed in a heating block set at $99^{\circ} \mathrm{C}$ for 60 minutes. After cooling to room temperature, the samples were centrifuged for 5 minutes at $12,100 \times g$ to separate the insoluble material. An aliquot $(4 \mu \mathrm{L})$ of the supernatant was transferred to $3 \mathrm{~mL}$ of $8 \mathrm{~mol} / \mathrm{L}$ urea/ $10 \mathrm{mmol} / \mathrm{L}$ Tris- $\mathrm{HCl}$, $\mathrm{pH} 8.0$, to determine protein concentration by fluorescence spectroscopy, as previously described. ${ }^{54}$ For IP, the solubilization procedure was identical, except that the extraction buffer contained $1 \%$ SDS and $10 \mathrm{mmol} / \mathrm{L}$ DTT.

For cell line lysates, cells grown on 10-cm dishes were lysed in ice-cold lysis buffer $(20 \mathrm{mmol} / \mathrm{L}$ Tris, $\mathrm{pH} 7.5,1 \%$ Triton X$100,150 \mathrm{mmol} / \mathrm{L} \mathrm{NaCl}, 1 \mathrm{mmol} / \mathrm{L}$ EDTA/EGTA, $10 \mathrm{mmol} / \mathrm{L}$ sodium pyrophosphate, $10 \mathrm{mmol} / \mathrm{L} \quad \beta$-glycerophosphate, 1 $\mathrm{mmol} / \mathrm{L}$ sodium orthovanadate, and $50 \mathrm{mmol} / \mathrm{L}$ sodium 
fluoride) and scraped into chilled tubes, then incubated on ice for 10 minutes, with brief vortexing every 2 to 3 minutes. Samples were centrifuged at $12,000 \times g$ for 10 minutes at $4^{\circ} \mathrm{C}$ to pellet insoluble material. The soluble fraction was mixed with $5 \times$ sample buffer $(312 \mathrm{mmol} / \mathrm{L}$ Tris, $\mathrm{pH} 6.8,10 \%$ SDS, $10 \% \beta$-mercaptoethanol, $50 \%$ glycerol, and $0.05 \%$ bromophenol blue) and boiled for 5 minutes at $95^{\circ} \mathrm{C}$, then cooled on ice. Total protein content of cell line lysates was assessed using bicinchoninic acid assay (Thermo Fisher Scientific; catalog number 23225).

Protein lysates were loaded onto $10 \%$ polyacrylamide gels and run for 30 minutes at $90 \mathrm{~V}$, then approximately 90 minutes at $120 \mathrm{~V}$. Proteins were transferred to $0.2 \mu \mathrm{mol} / \mathrm{L}$ pore nitrocellulose membranes and blocked for 60 minutes with 5\% nonfat milk in phosphate-buffered saline/0.05\% Tween-20. Primary antibodies were diluted in 5\% bovine serum albumin/phosphate-buffered saline $/ 0.05 \%$ Tween-20, and incubations were performed overnight at $4{ }^{\circ} \mathrm{C}$ with gentle shaking. Secondary antibodies were diluted in blocking buffer, and incubations were performed for 1 hour at room temperature. Images were acquired on the Bio-Rad ChemiDoc $\mathrm{XRS}^{+}$imaging system (Bio-Rad Laboratories, Hercules, CA).

\section{Immunoprecipitation}

Protein lysates from cell lines or FFPE tumors (see above; FFPE tumors were extracted in buffer containing $1 \%$ SDS, $125 \mathrm{mmol} / \mathrm{L}$ Tris- $\mathrm{HCl}, 10 \mathrm{mmol} / \mathrm{L}$ DTT, and $20 \%$ glycerol for IP) were diluted 1:12 with ice-cold lysis buffer (20 $\mathrm{mmol} / \mathrm{L}$ Tris, $\mathrm{pH} 7.5,1 \%$ Triton $\mathrm{X}-100,150 \mathrm{mmol} / \mathrm{L} \mathrm{NaCl}$, $1 \mathrm{mmol} / \mathrm{L}$ EDTA/EGTA, $10 \mathrm{mmol} / \mathrm{L}$ sodium pyrophosphate, $10 \mathrm{mmol} / \mathrm{L} \beta$-glycerophosphate, $1 \mathrm{mmol} / \mathrm{L}$ sodium orthovanadate, and $50 \mathrm{mmol} / \mathrm{L}$ sodium fluoride). The diluted lysates were precleared with Protein A magnetic beads (Cell Signaling Technology). Antibodies for Src (1:200), SFK_pY416 (1:200), or IgG control (Cell Signaling Technology; number 3900, 1:200) were added to the lysate and incubated overnight at $4{ }^{\circ} \mathrm{C}$ with gentle rocking. Protein A magnetic beads $(20 \mu \mathrm{L})$ were then added to the solution and incubated for 1 hour at $4{ }^{\circ} \mathrm{C}$ with gentle rocking. The beads were collected and washed five times with $1-\mathrm{mL}$ lysis buffer, and then bound proteins were eluted by heating the beads in $2 \times$ SDS sample buffer $(125 \mathrm{mmol} / \mathrm{L}$ Tris, $\mathrm{pH} 6.8$, $4 \%$ SDS, $20 \%$ glycerol, $100 \mathrm{mmol} / \mathrm{L}$ DTT, and $0.02 \%$ bromophenol blue) at $95^{\circ} \mathrm{C}$ for 5 minutes, followed by removal of the beads. The resulting IP eluate was analyzed by Western blot analysis, as described above.

\section{Analysis of Public Data Sets}

The Cancer Genome Atlas BRCA RNAseq data set was downloaded using Xena (University of California, Santa Cruz, https://xenabrowser.net/datapages/, last accessed December 12, 2018). Samples were separated into TNBC and non-TNBC subsets on the basis of human epidermal growth factor 2 receptor, estrogen receptor, and progesterone receptor expression. RNA expression data are presented as fragments per kilobase million-upper quartile (FPKM-UQ) values. Reverse phase protein array expression data were obtained from The Cancer Proteome Atlas (TCPA; MD Anderson Cancer Center, https://tcpaportal.org/tcpal download.html, last accessed December 12, 2018). The two data sets were aligned in R version 3.5.1 (R Foundation for Statistical Computing, Vienna, Austria) by matching sample identifiers. To confirm matching of samples, it was checked that reverse phase protein array expression values correlated well with The Cancer Genome Atlas (TCGA) mRNA expression values for the same gene.

\section{Statistical Analysis}

Statistical significance of immunohistochemical staining results was performed using the Pearson $\chi^{2}$ test. All correlation tests of TCGA/TCPA data were performed using the Pearson product moment correlation test, with significance of multiple comparisons tested by the false discovery rate method. ${ }^{55}$ Direct comparisons of two sample groups used unpaired $t$-test. All statistical analyses were performed in $\mathrm{R}$ version 3.5.1.

\section{Results}

F0XA1 Expression Identifies TNBC Subsets with Distinct Clinical and Pathologic Characteristics

To investigate SFK activation in TNBC and its interaction with CDCP1/PKC $\delta$ signaling, a set of FFPE blocks, representing 56 primary TNBCs resected between 2011 and 2017, was gathered. A punch biopsy sample of each tumor was removed from the parental block and reembedded to facilitate the manual assembly of small tissue microarrays and the extraction of individual samples for biochemical analysis. The full cohort of TNBC patient samples was characterized by IHC to evaluate expression of FOXA1, a nuclear chromatin binding protein required for $\mathrm{AR}$ function that is differentially expressed by LAR-TNBC, ${ }^{4,7}$ and vimentin, a mesenchymal intermediate filament protein. A complete list of samples used in this study and relevant clinical information are shown in Supplemental Table S1. Of the 56 TNBC foci, $24(43 \%)$ were FOXA1 positive $\left(\mathrm{FOXA1}^{+}\right)$. The clinical and pathologic features of the TNBC cohort are shown in Table 2 in relation to expression of FOXA1. Patients with FOXA $1^{+}$tumors were on average nearly 20 years older than those with FOXA1-negative $\left(\mathrm{FOXA1}^{-}\right)$tumors $(P=0.0008)$. All patients who presented with locally advanced disease (T3 or T4; 5 of 56 patients) had FOXA1 ${ }^{-}$ tumors. FOXA1 expression was not significantly associated with nodal stage; however, FOXA1 $1^{-}$tumors were more likely to be histologically high grade $(P=0.03)$ and to have a Ki-67 proliferation index $>30 \%(P=0.006)$. These 
Table 2 Clinical and Pathologic Features of TNBC Patient Samples in Relation to F0XA1 Expression

\begin{tabular}{|c|c|c|c|c|c|c|c|}
\hline \multirow[b]{2}{*}{ Characteristic } & \multicolumn{2}{|l|}{ Total } & \multicolumn{2}{|c|}{ F0XA1 negative } & \multicolumn{2}{|c|}{ F0XA1 positive } & \multirow[b]{2}{*}{$P$ value ${ }^{*}$} \\
\hline & Value & $\%$ & Value & $\%$ & Value & $\%$ & \\
\hline Patients, $n$ & 56 & & 32 & 57 & 24 & 43 & \\
\hline \multicolumn{8}{|l|}{ Age, years } \\
\hline$<50$ & 11 & 20 & 10 & 31 & 1 & 4 & 0.0008 \\
\hline $50-70$ & 25 & 45 & 16 & 50 & 9 & 38 & \\
\hline$>70$ & 20 & 36 & 6 & 19 & 14 & 58 & \\
\hline \multicolumn{8}{|l|}{ T stage } \\
\hline 1 & 15 & 27 & 7 & 22 & 8 & 33 & 0.04 \\
\hline 2 & 36 & 64 & 20 & 63 & 16 & 67 & \\
\hline $3 / 4$ & 5 & 9 & 5 & 16 & 0 & 0 & \\
\hline \multicolumn{8}{|l|}{ N stage } \\
\hline NA & 7 & & 2 & & 5 & & \\
\hline 0 & 33 & 67 & 23 & 77 & 10 & 53 & \\
\hline 1 & 10 & 20 & 4 & 13 & 6 & 32 & \\
\hline $2 / 3$ & 6 & 12 & 3 & 10 & 3 & 16 & \\
\hline \multicolumn{8}{|c|}{ Nottingham histologic grade } \\
\hline 1 & 0 & 0 & 0 & 0 & 0 & 0 & 0.03 \\
\hline 2 & 6 & 11 & 1 & 3 & 5 & 21 & \\
\hline 3 & 50 & 89 & 31 & 97 & 19 & 79 & \\
\hline \multicolumn{8}{|l|}{ Ki-67 } \\
\hline$\leq 30$ & 8 & 14 & 1 & 3 & 7 & 29 & 0.006 \\
\hline$>30$ & 48 & 86 & 31 & 97 & 17 & 71 & \\
\hline \multicolumn{8}{|c|}{ Mesenchymal and myoepithelial markers } \\
\hline \multicolumn{8}{|c|}{ Vimentin } \\
\hline Negative & 18 & 32 & 5 & 16 & 13 & 54 & 0.002 \\
\hline Positive & 38 & 68 & 27 & 84 & 11 & 46 & \\
\hline \multicolumn{8}{|l|}{ Sox10 } \\
\hline Negative & 14 & 41 & 2 & 11 & 12 & 75 & 0.0002 \\
\hline Positive & 20 & 59 & 16 & 89 & 4 & 25 & \\
\hline \multicolumn{8}{|l|}{ CK5/6 } \\
\hline Negative & 10 & 48 & 6 & 46 & 4 & 50 & \\
\hline Positive & 11 & 52 & 7 & 54 & 4 & 50 & \\
\hline \multicolumn{8}{|l|}{ SFK_pY416 } \\
\hline Negative & 33 & 59 & 17 & 53 & 16 & 67 & 0.1 \\
\hline Positive, $5 \%-20 \%$ & 10 & 18 & 5 & 16 & 5 & 21 & \\
\hline Positive, $>20 \%$ & 13 & 23 & 10 & 31 & 3 & 13 & \\
\hline
\end{tabular}

${ }^{*} P$ values calculated using Pearson $\chi^{2}$ test.

CK, cytokeratin; FOXA, forkhead box protein A; NA, not applicable; Sox, Sry-box; TNBC, triple-negative breast cancer.

findings indicate that FOXA1 expression identifies a clinically and pathologically distinct subset of TNBCs.

$\mathrm{BL}$ and mesenchymal TNBCs are reported to frequently express vimentin, a marker for epithelial-mesenchymal transition, ${ }^{56-58}$ but the extent to which vimentin is expressed in LAR-TNBC is not well defined. To address this, vimentin expression was assessed in our TNBC cohort. In fact, $46 \%(11 / 24)$ of $\mathrm{FOXA}^{+}$TNBCs expressed vimentin. In contrast, vimentin expression was observed in $84 \%$ (27/32) of FOXA1 ${ }^{-}$TNBCs (Table 2). A subset of the cohort for putative BL-TNBC markers SOX10 and CK5/6 was also stained. SOX10 expression was significantly associated with absence of FOXA1, but CK5/6 was expressed in approximately $50 \%$ of both $\mathrm{FOXA}^{+}$and FOXA $1^{-}$tumors (Table 2). In summary, $43 \%$ of this TNBC cohort expressed FOXA1, a nuclear protein associated with the LAR-TNBC subtype. ${ }^{3,7}$ FOXA1 $^{+}$tumors were from significantly older patients and more frequently were histologic grade 2, clinical features associated with LARTNBC. $^{7}$ In addition, FOXA1 expression had a significant negative correlation with expression of SOX10, a marker associated with BL-TNBC. ${ }^{59}$ On the basis of these findings, we suggest that most of the FOXA $1^{+}$tumors in this cohort are LAR-TNBC.

High Levels of SFK_pY416 Are Observed Predominantly in $\mathrm{FOXA1}^{-} /$Vimentin $^{+} \mathrm{TNBC}^{-}$

To identify TNBC with active SFK signaling, tissue sections were stained with a commercially available antibody recognizing multiple SFK isoforms phosphorylated at Y416. SFK_pY416 was detected immunohistochemically in tumor 
A

TNBC-52

(SFK_pY416 ${ }^{+}$)

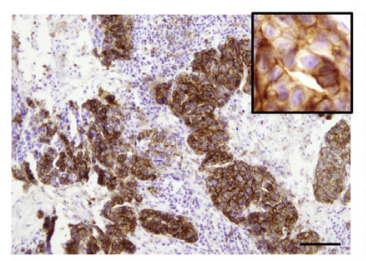

CDCP1 pY743

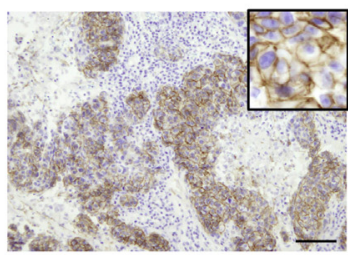

B

TNBC-7

(Focal/low

SFK_pY416 )

C

TNBC-11

(SFK_pY416-)
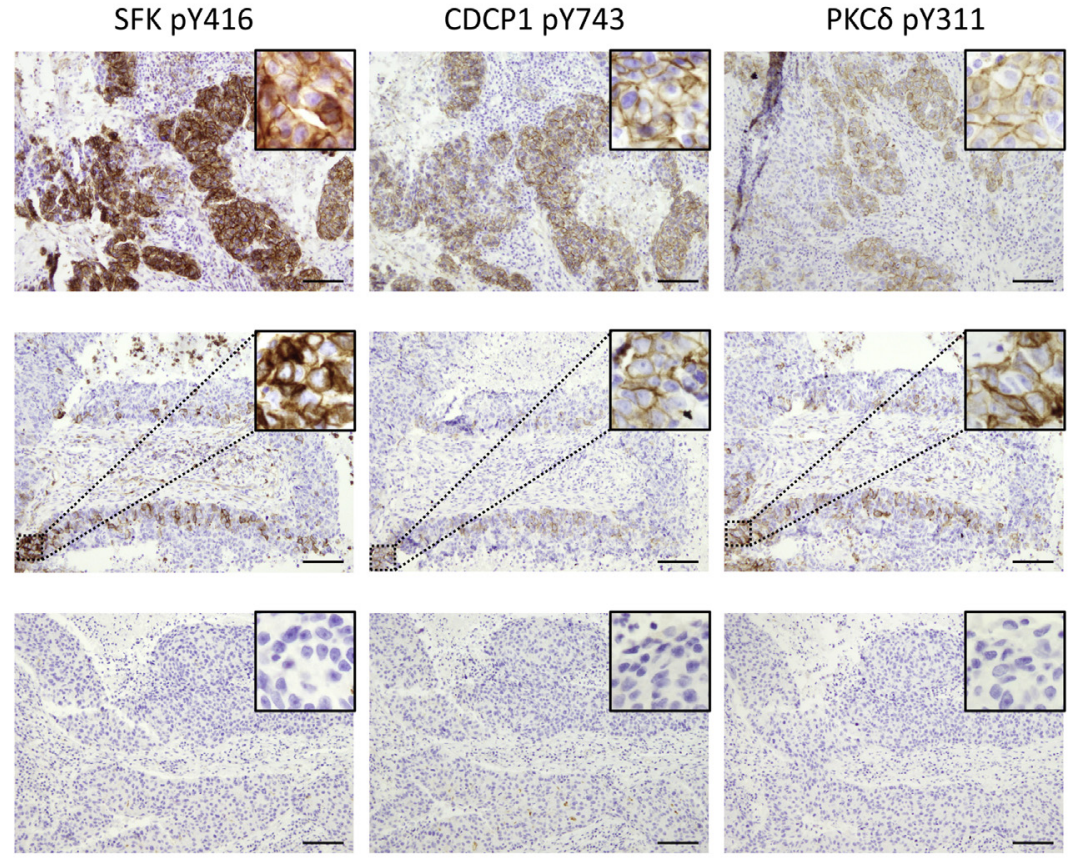

D

\section{Protein}

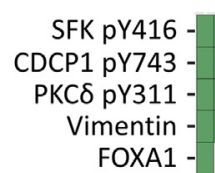

Protein expression heat map for cohort of 56 TNBC

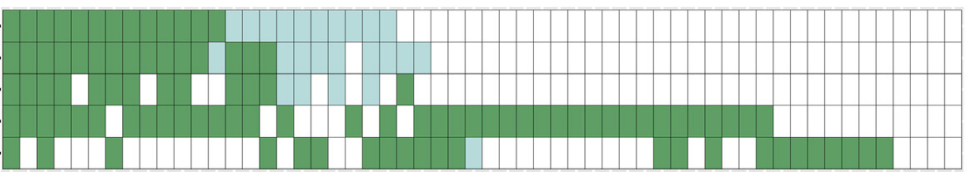

\section{Expression Scale}

Positive (>20\%)

Focal/low ( $\leq 20 \%)$

Negative

Figure 1 SFK substrates CUB-domain containing protein 1 (CDCP1) and protein kinase $C \delta$ (PKC $\delta$ ) are phosphorylated in SFK_pY416 positive triple-negative breast cancer (TNBC). A: Representative patient sample with diffuse immunohistochemical staining of tumor cells for SFK_pY416, CDCP1_pY743, and PKCä_pY311. Staining for each marker was detected primarily on the cell membrane. Negative cells are predominantly stromal lymphocytes. B: Representative patient sample with a focal/low $(<20 \%)$ pattern of staining for SFK_pY416, CDCP1_pY743, and PKCä_pY311 in tumor cells. C: Representative patient sample with negative staining. Insets: Areas of interest at higher magnification to show detail. D: Summary of staining results in panel of 56 TNBC samples. Main images were acquired using a $10 \times$ objective, and insets were acquired using a $40 \times$ objective. Scale bars $=100 \mu \mathrm{m}(\mathbf{A}-\mathbf{C})$. FOXA, forkhead box protein.

cells in 23 of the 56 TNBCs (41\%). The staining pattern was predominantly membranous (Figure 1, A and B). This finding is consistent with reports indicating that SFK activation occurs predominantly at the cell membrane. ${ }^{34} \mathrm{~A}$ similar staining pattern was reported by Anbalagan et $\mathrm{al}^{60}$ in their study of TNBC samples. The percentage of SFK_pY416 ${ }^{+}$tumor cells ranged from $5 \%$ to $100 \%$ (median, 50\%) (Supplemental Table S1). There was no association between SFK_pY416 expression and patient age, tumor stage, nodal stage, histologic grade, or Ki-67 proliferation index (Table 3). Expression of SFK_pY416 was detected more often in FOXA1 ${ }^{-}$samples, but this trend did not reach statistical significance $(P=0.1)$, likely because of the limited cohort size. There was also an association between high levels of SFK_pY416 expression and expression of vimentin. Of the 13 tumors in which $>20 \%$ of tumor cells expressed SFK_pY416, 12 also expressed vimentin $(P=0.03)$. The association between SFK_pY416 expression and vimentin was not observed in tumors with focal/ low ( $\leq 20 \%$ positive cells) expression of SFK_pY416. A subset of the TNBC foci in this cohort was evaluated for expression of additional markers associated with epithelialmesenchymal transition, including Slug and N-cadherin, and no clear association with SFK_pY416 was identified (data not shown). In summary, IHC analysis identified SFK_pY416 staining in $41 \%$ of TNBCs. High expression of SFK_pY416 ( $>20 \%$ of tumor cells) was observed more frequently in $\mathrm{FOXA}^{-} /$vimentin $^{+}$tumors.

\section{Expression of SFK_pY416 Is Associated with Phosphorylation of SFK Substrates CDCP1 and PKC $\delta$ in Tumor Cells}

To confirm that positive SFK_pY416 staining is an indication of SFK activity, the phosphorylation of two SFK substrates, CDCP1 and $\mathrm{PKC} \delta,{ }^{39,48}$ was evaluated by IHC (Figure 1). Like SFK_pY416, the staining pattern of CDCP1 phosphorylated at Y743 (CDCP1_pY743) and 
Table 3 Clinical and Pathologic Features of TNBC Patient Samples in Relation to High (>20\%) SFK_pY416 Expression

\begin{tabular}{|c|c|c|c|c|c|c|c|}
\hline \multirow[b]{2}{*}{ Characteristic } & \multicolumn{2}{|l|}{ Total } & \multicolumn{2}{|c|}{ SFK_pY416 negative/low $(<20 \%)$} & \multicolumn{2}{|c|}{$\underline{\text { SFK_pY416 positive }(>20 \%)}$} & \multirow[b]{2}{*}{$P$ value* } \\
\hline & Value & $\%$ & Value & $\%$ & Value & $\%$ & \\
\hline Patients, $n$ & 56 & & 43 & 77 & 13 & 23 & \\
\hline$<50$ & 11 & 20 & 9 & 21 & 2 & 15 & \\
\hline $50-70$ & 25 & 45 & 20 & 47 & 5 & 38 & \\
\hline$>70$ & 20 & 36 & 14 & 33 & 6 & 46 & \\
\hline 2 & 36 & 64 & 27 & 63 & 9 & 69 & \\
\hline $3 / 4$ & 5 & 9 & 4 & 9 & 1 & 8 & \\
\hline \multicolumn{8}{|l|}{$\mathrm{N}$ stage } \\
\hline NA & 7 & & 5 & & 2 & & \\
\hline 0 & 33 & 67 & 27 & 63 & 6 & 46 & \\
\hline 2 & 6 & 11 & 5 & 12 & 1 & 8 & \\
\hline 3 & 50 & 89 & 38 & 88 & 12 & 92 & \\
\hline \multicolumn{8}{|l|}{ Ki-67 } \\
\hline$\leq 30$ & 8 & 14 & 6 & 14 & 2 & 15 & \\
\hline$>30$ & 48 & 86 & 37 & 86 & 11 & 85 & \\
\hline \multicolumn{8}{|l|}{ Vimentin } \\
\hline Negative & 18 & 14 & 17 & 40 & 1 & 8 & 0.03 \\
\hline Positive & 38 & 86 & 26 & 60 & 12 & 92 & \\
\hline \multicolumn{8}{|l|}{ F0XA1 } \\
\hline Negative & 18 & 14 & 22 & 51 & 10 & 77 & \\
\hline Positive & 38 & 86 & 21 & 49 & 3 & 23 & \\
\hline \multicolumn{8}{|l|}{ CDCP1 pY743 } \\
\hline
\end{tabular}

${ }^{*} P$ values calculated using Pearson $\chi^{2}$ test.

CDCP, CUB-domain containing protein; FOXA, forkhead box protein; NA, not applicable; PKC, protein kinase C; TNBC, triple-negative breast cancer.

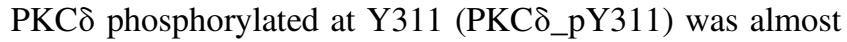
entirely membranous. Twenty-four foci (43\%) were CDCP1_pY743 ${ }^{+}$and 17 foci $(30 \%)$ were PKC $\delta \_p Y 311^{+}$. The percentage of CDCP1_pY743 ${ }^{+}$tumor cells ranged from $5 \%$ to $100 \%$ (median, 55\%); the percentage of

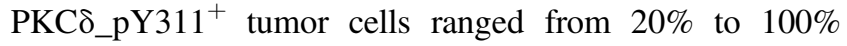
(median, 60\%). Expression of the three phosphoproteins in the $\mathrm{SFK} / \mathrm{CDCP} 1 / \mathrm{PKC} \delta$ pathway was highly correlated using $>20 \%$ positive cells as a threshold $\left(P<10^{-4}\right)$ (Table 3). Furthermore, CDCP1_pY743 and PKC $\delta \_p Y 311$ staining colocalized with SFK_pY416, even in samples with focal/low $(\leq 20 \%)$ expression of SFK_pY416 (Figure 1, B and D). Together, these results suggest that SFK_pY416 staining is a valid marker for SFK activation in TNBC and that SFK activation in TNBC tumor cells is usually accompanied by phosphorylation of the SFK substrates CDCP1 and PKC 8 .
Western Blot Analysis Confirms IHC Results and Reveals Co-Expression of SFK_pY416 and SFK_pY527 in Tumor Samples

The IHC data were validated with Western blot analysis of protein lysates extracted from FFPE tissue samples: all samples that tested positive for SFK_pY416 by IHC also showed a specific band at $60 \mathrm{kDa}$ for SFK_pY416 (Figure 2A). Lysate from the TNBC cell line MDA-MB231, which is known to have an active SFK/CDCP1/ $\mathrm{PKC} \delta$ pathway, was used as a positive control (Figure 2A). ${ }^{44,49}$ The cleavage of the extracellular domain of CDCP1 promotes its activity. ${ }^{44,61}$ Western blot analysis was crucial to investigate the CDCP1 cleavage pattern associated with SFK activation, as the two CDCP1 isoforms cannot be distinguished by IHC because of the lack of antibodies that specifically recognize the cleaved isoform. 
CDCP1 was cleaved to varying degrees in all tumor foci analyzed, independent of SFK phosphorylation at Y416 (Figure 2A). As predicted by IHC findings, CDCP1_pY743 was detected by Western blot analysis almost exclusively in tumors in which SFK_pY416 and CDCP1_pY743 were detected by IHC (Figure 2A). Interestingly, all tumor foci that were SFK_pY416 ${ }^{+}$were also SFK_pY527 ${ }^{+}$, the canonical marker of inactive SFK (Figure 2A). Analysis of SFK_pY416 ${ }^{-}$tumors in the context of FOXA1 expression revealed differences in SFK phosphorylation patterns. Of the five SFK_pY416 ${ }^{-}$samples, two have the classic inactive SFK phosphorylation pattern pY416 $/ 6^{-} \mathrm{p}^{2} 27^{+}$(Figure 2A), and both are FOXA1 ${ }^{+}$. The other three samples show no evidence of SFK phosphorylation at either Y416 or Y527 (Figure 2A), and these tumors are FOXA1 ${ }^{-}$.

To investigate the association between SFK_pY416 and SFK_pY527 further, a public data set from TCPA, an arm of TCGA that used reverse phase protein array to quantify protein-level expression data, ${ }^{62}$ was interrogated. In agreement with the data presented in Figure 2A, of 224 proteins

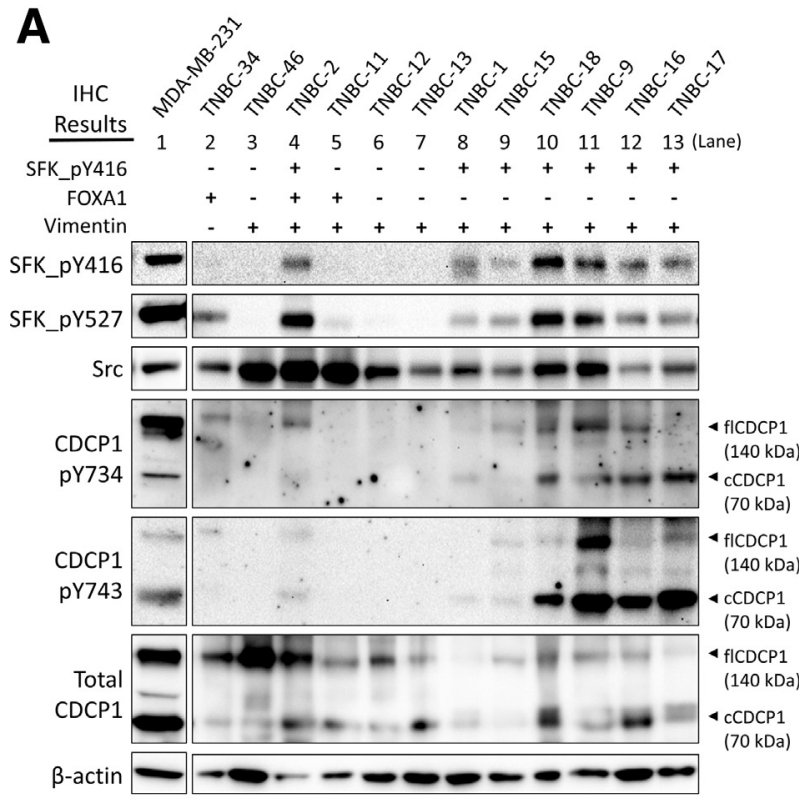

B

$$
\text { TCPA proteins correlated with }
$$
SFK_pY416 in TNBC

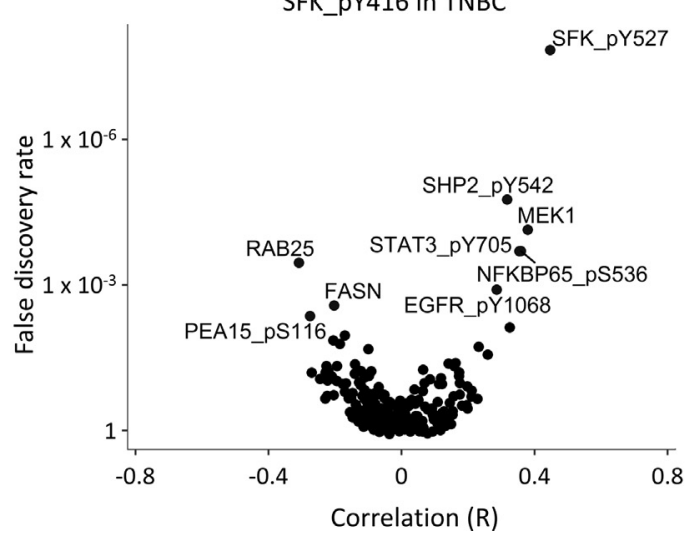

analyzed in TCPA, SFK_pY416 most strongly correlated with SFK_pY527 (Figure 2B). Other highly correlated protein markers included three phosphorylated proteins-Src homology region 2-containing protein tyrosine phosphatase 2 (SHP2), epidermal growth factor receptor, and STAT3 - all of which are known to be associated with increased SFK activity. ${ }^{37,63,64}$ Fatty acid synthetase, known to be highly expressed in LAR-TNBC, ${ }^{3,7}$ negatively correlated with SFK_pY416 (Figure 2B). CDCP1 and PKC $\delta$ phosphorylation were not evaluated in this 224-protein data set. The co-expression of SFK_pY416 and SFK_pY527, shown in patient samples in Figure 2, suggests a possibility that individual SFK molecules are biphosphorylated.

\section{Analysis of SFK_pY416, Isolated by Immunoprecipitation, Confirms the Presence of Biphosphorylated SFK in TNBC}

To provide more direct evidence for existence of biphosphorylated SFK in TNBC, SFK_pY416, isolated by IP, was analyzed for the presence of SFK_pY527. To perform IP, FFPE solubilization procedure was optimized to achieve the SDS concentration compatible with IP. A reducing agent, such as DTT, is critical for optimal solubilization of proteins from FFPE (unpublished observations, L.J.N. and F.S.H.). Two FFPE tumor samples were extracted with buffers that varied in SDS and DTT

Figure 2 SFK_pY416 and SFK_pY527 are co-expressed in triple-negative breast cancer (TNBC). A: Western blot analysis confirms the co-expression of phosphorylated SFK/CUB-domain containing protein 1 (CDCP1) proteins, as determined by immunohistochemistry (IHC), and shows the coexpression of SFK_pY416 and SFK_pY527. Paraffin sections of TNBC were extracted and analyzed by standard Western blot analysis technique. forkhead box protein 1 (FOXA1), vimentin, and SFK_pY416 expression levels in tumor cells, as determined by IHC, are summarized on top. Probing with SFK_pY416 antibody detects a $60-\mathrm{kDa}$ band in all patient samples that were SFK_pY $416^{+}$by IHC (lanes 4 and 8 to 13) and does not detect the band in patient samples that were SFK_pY416- ${ }^{-}$by IHC. Cleaved CDCP1_pY734, CDCP1_pY743, and SFK_pY527 are co-expressed with SFK_pY416. Whole cell lysate from the TNBC cell line MDA-MB-231 was used as a positive control (lane 1). TNBC-2 (lane 4) has granular cytoplasmic staining for SFK_pY416. All other SFK_pY416 ${ }^{+}$tumors had membrane staining. Equal amounts of protein were loaded to each lane, as quantitated by tryptophan fluorescence spectrometry. $\beta$-Actin was used as a loading control. B: Analysis of TNBC proteome in silico showing top eight proteins (protein names displayed next to data point) whose expression is correlated with SFK_pY416, with SFK_pY527 exhibiting the strongest correlation. TNBC tumor samples were isolated from The Cancer Proteome Atlas (TCPA) breast cancer (BRCA) data set by negativity for estrogen receptor, progesterone receptor, and human epidermal growth factor 2 receptor and analyzed for correlation of protein markers. Correlations were derived by Pearson product moment correlation test. CCDCP1, cleaved CDCP1; EGFR, epidermal growth factor receptor; FASN, fatty acid synthase; fICDCP1, full-length CDCP1; MEK1, dual specificity mitogen-activated protein kinase kinase 1 ; NFKBp65, nuclear factor NF-kappa-B p65 subunit; PEA15, astrocytic phosphoprotein PEA-15; RAB25, Ras-related protein rab-25; SFK, Src family kinase; SHP2, Src homology region 2-containing protein tyrosine phosphatase; STAT3, signal transducer and activator of transcription 3. 
A

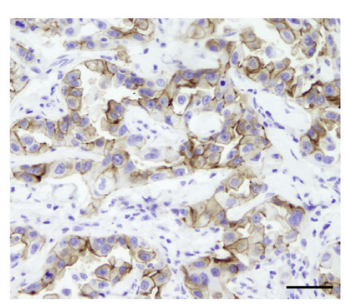

B

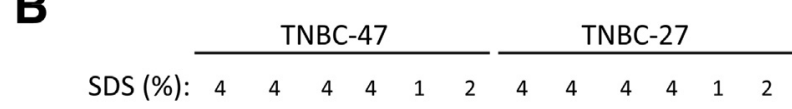

DTT (mmol/L): $0 \quad 1 \quad 10100100100 \quad 0 \quad 1 \quad 10100100100$

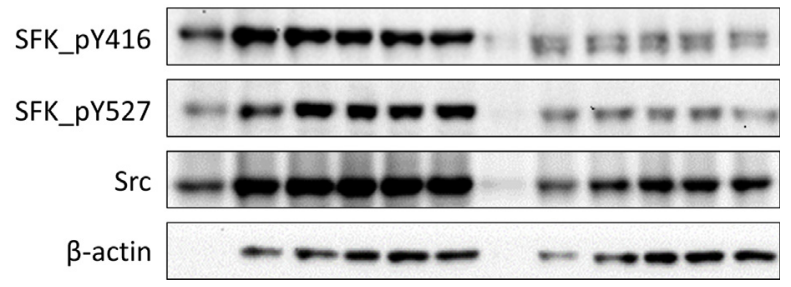

Figure 3 Optimization of dithiothreitol (DTT) and SDS concentrations for solubilization of formalin-fixed, paraffin-embedded (FFPE) protein compatible with immunoprecipitation. A: Representative images of SFK_pY416 staining of two FFPE triple-negative breast cancer (TNBC) tumors used in extraction optimization and Figure 4. TNBC-47 contains SFK_pY $416^{+}$tumor cells and SFK_pY416 ${ }^{-}$tumor-infiltrating lymphocytes (TILs), whereas TNBC-27 contains SFK_pY416 ${ }^{+}$tumor cells and SFK_pY416 ${ }^{+}$ TILs. B: Western blot analysis of phosphorylated SFK and total Src in protein samples extracted using variable amounts of DTT and SDS sets the effective concentrations to $100 \mathrm{mmol} / \mathrm{L} \mathrm{DTT} / 1 \%$ SDS or $10 \mathrm{mmol} / \mathrm{L} \mathrm{DTT} / 4 \%$ SDS. Equal FFPE tissue volumes were used for each extraction, and equal volumes of extract were loaded to each lane. Scale bars $=50 \mu \mathrm{m}(\mathbf{A})$.

concentrations (Figure 3). TNBC-47 exhibits strong and diffuse staining for SFK_pY416 in tumor cells and a tumor-infiltrating lymphocyte (TIL) population that is SFK_pY416 ${ }^{-}$(Figure 3A). In contrast, TNBC-27 exhibits both tumor cells and TILs that are SFK_pY416 ${ }^{+}$ (Figure 3A). Even in the presence of $4 \%$ SDS, optimal solubilization of proteins requires $10 \mathrm{mmol} / \mathrm{L} \mathrm{DTT}$; on the other hand, in the presence of $100 \mathrm{mmol} / \mathrm{L}$ DTT, extraction with $1 \%$ SDS is as efficient as $4 \%$ SDS (Figure 3B).

Analysis of SFK_pY416, isolated from MDA-MB-231 cells under optimized extraction conditions, clearly demonstrates biphosphorylation of SFK. Probing the SFK_pY416 IP with SFK_pY527 antibody detected a strong protein band, indicating that at least a portion of the SFK_pY416 ${ }^{+}$population is also phosphorylated at Y527 (Figure 4A). IP with the SFK_pY416 antibody was specific because probing the SFK_pY416 IP with an antibody specific for SFK not phosphorylated at Y416 (SFK_nonpY416) showed no signal (Figure 4A). A similar result was obtained with protein extracted from TNBC-47 and TNBC-27 (Figure 4B). To determine which SFK isoforms were precipitated by SFK_pY416 antibody from these two TNBCs, the IP was probed for Src, Lyn, and Lck. Lyn is reported to be up-regulated and active in TNBC, ${ }^{24,26}$ and Lck is essential for T-cell activation. ${ }^{65,66}$ In the TNBC-47 sample without SFK_pY416 ${ }^{+}$TILs, Src was the only isoform detected in SFK_pY416 IP (Figure 4B). In the TNBC-27 sample with SFK_pY416 ${ }^{+}$TILs, both Src and Lck were detected in SFK_pY416 IP (Figure 4B). There is a correlation between expression of multiple SFK isoforms [tyrosine-protein kinase Yes (Yes), tyrosine-protein kinase Fyn (Fyn), and tyrosine-protein kinase Hck (Hck)] and expression of SFK_pY416 in the TNBC cohort in TCGA (Supplemental Figure S1), but the presence of other SFK isoforms in TNBC tumor samples was not addressed in this study. In summary, these data indicate that SFK is

A

\section{MDA-MB-231}

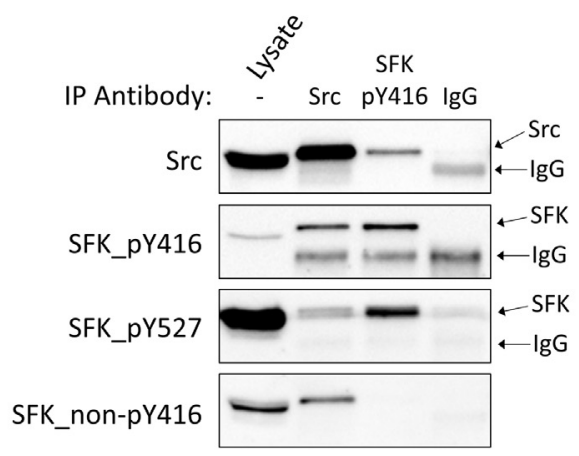

B
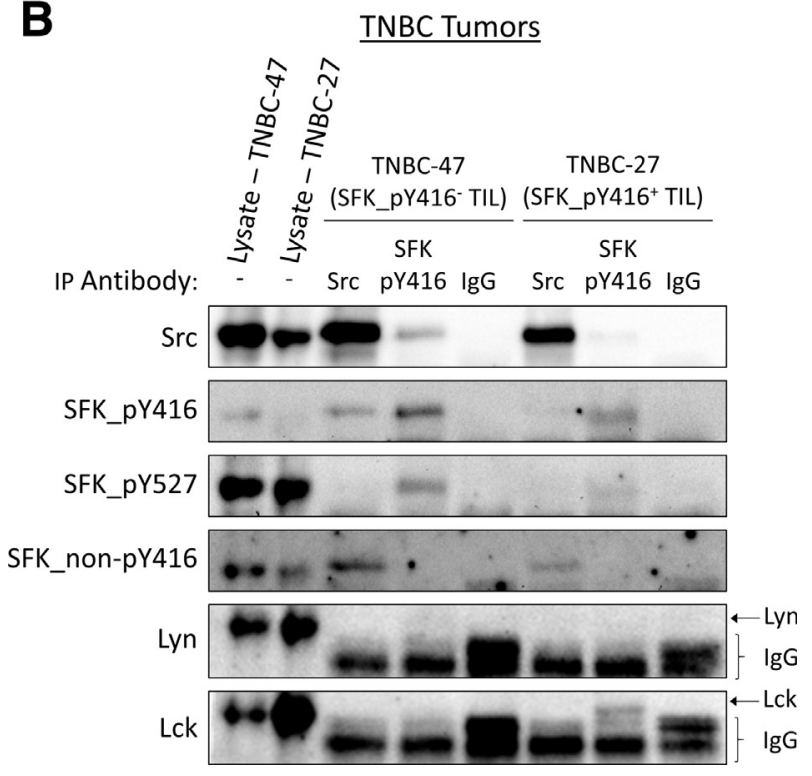

Figure 4 Immunoprecipitation of SFK_pY416 followed by Western blot analysis of SFK_pY527 shows that SFK molecules are biphosphorylated at Y416 and Y527 in triple-negative breast cancer (TNBC). Protein lysates from MDA-MB-231 cells (A) and TNBC-47 and TNBC-27 formalin-fixed, paraffinembedded tumor samples (B) were immunoprecipitated with the antibodies indicated on top, and then analyzed by Western blot analysis with antibodies indicated on the left. Probing the SFK_pY416 precipitate with an antibody specific for SFK not phosphorylated at Y416 (SFK_non-pY416) shows no signal after immunoprecipitation (IP). TNBC-47 sample with no SFK_pY416 ${ }^{-}$tumor-infiltrating lymphocytes (TILs) shows SFK_pY416 ${ }^{+}$Src only. TNBC-27 sample with SFK_pY416 ${ }^{+}$TILs shows both SFK_pY416 ${ }^{+}$Src and leukocyte C-terminal Src kinase (Lck). No SFK_pY416 ${ }^{+}$Lck/Yes-related novel protein tyrosine kinase (Lyn) is detected in either sample. 
biphosphorylated at Y416 and Y527 on the same molecule in a TNBC cell line and patient tumors.

TNBCs without SFK Activation (SFK_pY416 ${ }^{-}$) Have a Difference in Y527 Phosphorylation between F0XA1 ${ }^{+}$ and FOXA1 ${ }^{-}$Tumors

Two FOXA1 ${ }^{+}$tumors that were SFK_pY416 ${ }^{-}$and SFK_pY527 ${ }^{+}$were observed, whereas three FOXA1 ${ }^{-}$tumors were SFK_pY416 ${ }^{-}$and SFK_pY527 ${ }^{-}$(Figure 2).
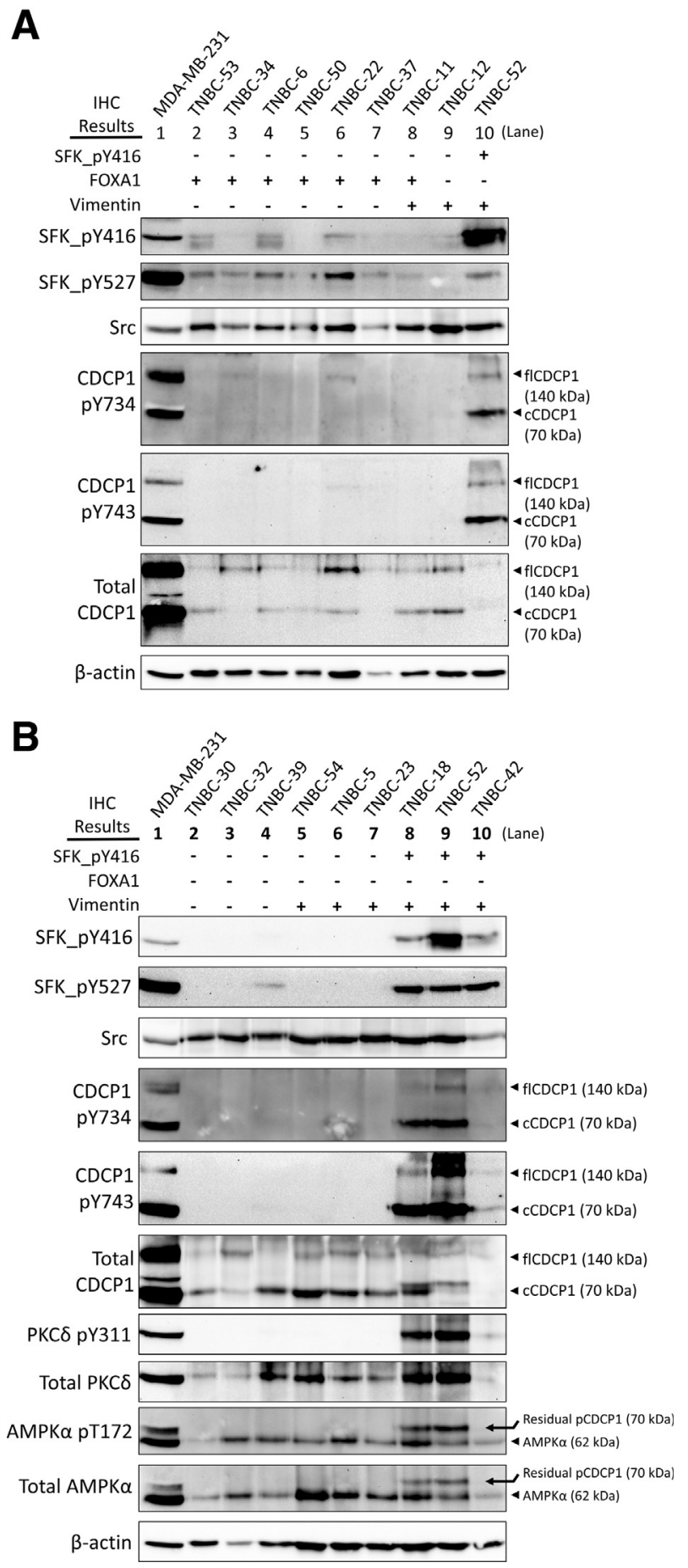

This prompted us to analyze additional tumors that were SFK_pY416 ${ }^{-}$to see if the differential pattern of SFK_pY527 phosphorylation could be generalized. Indeed, SFK_pY527 was detected in seven additional SFK_pY416 ${ }^{-} /$FOXA $^{+}$tumors (Figure 5A). A small amount of SFK_pY416 was detected by Western blot analysis in three of the samples, which were SFK_pY416 by IHC (Figure 5). To address this discrepancy between the Western blot analysis and IHC results, the IHC staining was reanalyzed and SFK_pY416 was observed in TILs, not tumor cells (Supplemental Figure S2). When six SFK_pY $416^{-} / \mathrm{FOXA1}^{-}$foci were analyzed by Western blot analysis, five contained no detectable SFK_pY527 (Figure 5B).

In summary, all TNBC samples in this study with $>20 \%$ SFK_pY416 ${ }^{+}$tumor cells contained high levels of both SFK_pY416 and SFK_pY527 (nine of nine samples). In samples without SFK_pY416 in tumor cells (SFK_pY416 ${ }^{-}$), FOXA1 ${ }^{+}$TNBC tended to be SFK_pY527 $7^{+}$(seven of seven samples; classic inactive SFK), and FOXA1 ${ }^{-}$TNBC tended to be SFK_pY527(eight of nine samples). Because phosphorylation of SFK_Y527 stabilizes an inactive SFK conformation, FOXA $1^{-}$TNBC may carry a form of SFK that is poised for activation.

\section{Expression of SFK_pY416 in TNBC TILs Is Associated with High TIL Content and Expression of Inflammatory and Immune Response Genes}

To assess the gene expression changes associated with SFK activation in TNBC, TNBC samples from TCGA were separated into SFK_pY416 ${ }^{\mathrm{hi}}$ and SFK_pY416 ${ }^{\mathrm{lo}}$ groups and differentially expressed genes were identified. A heat map representing the top 100 genes positively and negatively correlated with SFK_pY416 is displayed in Figure 6A. The full heat map of positively regulated genes is shown in Supplemental Figure S3. The positively correlated genes were analyzed using Gene Ontology analysis through the

Figure 5 Western blot analysis of SFK_pY416 ${ }^{-}$triple-negative breast cancer (TNBC) reveals that forkhead box protein 1 (FOXA1) ${ }^{+}$samples tend to be SFK_pY527 ${ }^{+}$and FOXA1 ${ }^{-}$samples tend to be SFK_pY527 ${ }^{-}$. Paraffin sections of TNBC were extracted and analyzed by standard Western blot analysis technique. FOXA1, vimentin, and SFK_pY416 expression levels in tumor cells, as determined by immunohistochemistry (IHC), are summarized on top. A: All FOXA1 ${ }^{+} /$SFK_pY416 ${ }^{-}$samples tested were SFK_pY527 ${ }^{+}$. The presence of SFK_pY416 in lanes 2, 4, and 6 is due to the presence of SFK_pY $416^{+}$lymphocytes in these tumor samples (shown in Supplemental Figure S1). B: Five of six FOXA1 ${ }^{-} / \mathrm{SFK} \_\mathrm{pY} 416^{-}$samples tested were SFK_pY527 ${ }^{-}$(lanes 2, 3, and 5 to 7). Three FOXA1 ${ }^{-} /$SFK_pY416 ${ }^{+}$tumor samples were run as controls. All samples contain phosphorylated AMPactivated protein kinase alpha (AMPK $\alpha$ ) as a uniformly phosphorylated control for phosphoprotein extraction. Equal amounts of protein were loaded to each lane, as quantitated by tryptophan fluorescence spectrometry. $\beta$-Actin was used as a loading control. CCDCP1, cleaved CDCP1; CDCP1, CUB-domain containing protein 1; fLCDCP1, full-length CDCP1; PKC, protein kinase $\mathrm{C}$. 
A

TCGA Transcripts correlate with SFK_pY416 in TNBC

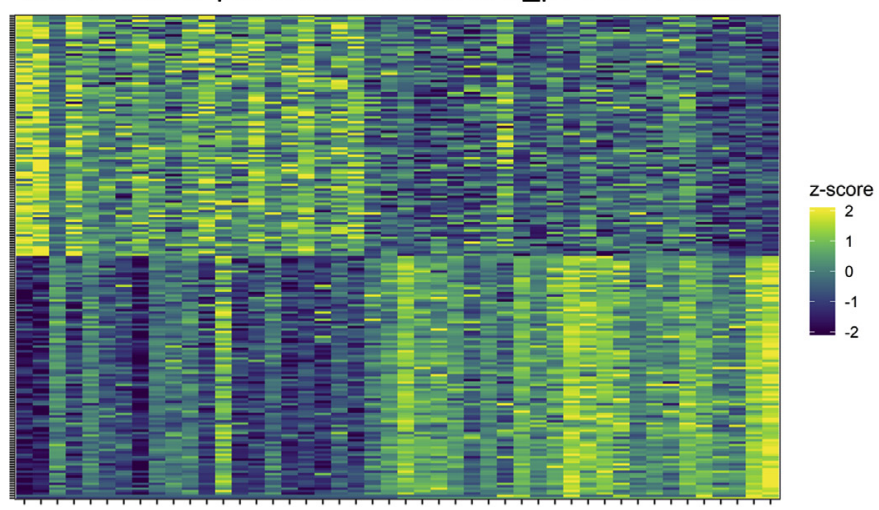

pY416 lo samples
pY416 hamples
B

GO terms positively correlated

with SFK pY416 in TNBC

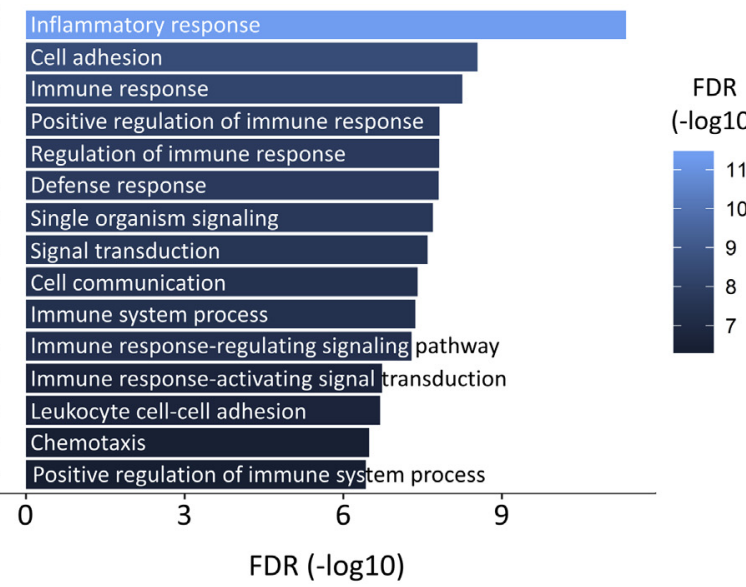

C
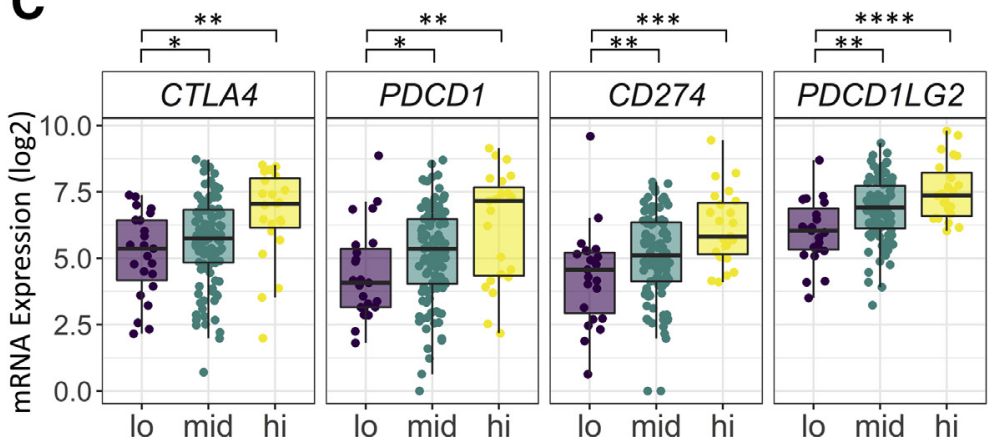

Figure 6 In silico analysis of The Cancer Genome Atlas (TCGA)/The Cancer Proteome Atlas data sets reveals that expression of SFK_pY416 in triple-negative breast cancer (TNBC) is associated with expression of inflammatory and immune response genes. A: Heat map depicting relative expression of mRNA transcripts that correlate with expression of SFK_pY416 in TNBC. TNBC tumors were isolated from breast cancer (BRCA) TCGA data set on the basis of negativity for estrogen receptor, progesterone receptor, and human epidermal growth factor 2 receptor. TNBC samples were separated into SFK_pY416 ${ }^{\text {hi }}$ (top 15\%) and SFK_pY $416^{\text {lo }}$ (bottom 15\%) for presentation purposes to highlight differences in gene expression. The positively correlating gene names are provided in Supplemental Figure S3. B: Gene Ontology (G0) analysis of top 100 genes correlated with SFK_pY416 expression reveals enrichment in genes involved in immune and inflammatory responses. No significant enrichment terms were discovered for the top 100 genes negatively correlated with SFK_pY416 expression (data not shown). C: Expression of immune checkpoint genes increases as SFK_pY416 increases in TNBC samples. PDCD1 encodes PD1 protein; CD274 encodes PD-L1 protein; and PDCD1LG2 encodes PD-L2 protein. $P$ values were derived by unpaired $t$ test. ${ }^{*} P<0.05,{ }^{* *} P<0.01,{ }^{* * *} P<0.001$, and ${ }^{* * * *} P<0.0001$. FDR, false discovery rate; hi, high; lo, low; mid, middle; PD1, programmed cell death protein 1; PD-L, programmed cell death 1 ligand.

STRING database. ${ }^{67}$ Samples with high SFK_pY416 showed a strong enrichment for genes involved in immune and inflammatory processes as well as cytokine/chemokine signaling (Figure 6B). Several of these genes have been reported as overexpressed in the immunomodulatory TNBC phenotype described by Lehmann et $\mathrm{al}^{7,8}$ and the basal-like immune activated TNBC phenotype described by Burstein et al. ${ }^{9}$ The top negatively correlated genes did not show any significantly enriched Gene Ontology terms with this method (data not shown). Because an immune signature and expression of immune checkpoint genes may have significance for immunotherapy, ${ }^{68}$ the expression of genes encoding CTLA-4, PD-1, PD-L1, and PD-L2 was analyzed in relation to SFK_pY416. All four genes showed a significant increase in SFK_pY416 ${ }^{\text {hi }}$ samples (Figure 6C).

To further investigate the correlation between SFK activation and expression of immune checkpoint proteins in
TNBC, a large subset of our TNBC cohort was stained for CD3, CTLA-4, PD-1, and PD-L1. Their protein expression in each tumor was estimated by visual assessment of the density of positively staining cells and the intensity of the staining. The results were compared with similar measurements of SFK_pY416 in tumor cells and lymphocytes. No correlation was observed between tumor SFK_pY416 and any of the immune markers examined (Figure $7 \mathrm{~A}$ and Table 4). In contrast, there was a modest, but significant, correlation between lymphocyte SFK_pY416 and all five measures of immune cell infiltration (Figure $7 \mathrm{~B}$ and Table 4). The correlation between lymphocyte SFK_pY416 and TIL, CD3, and immune checkpoint proteins was driven by tumors that expressed high levels of all of these markers (Figure 7B), and limited by tumors that expressed relatively little lymphocyte SFK_pY416 but high levels of $\mathrm{CD}^{+} \mathrm{T}$ cells and immune checkpoint 

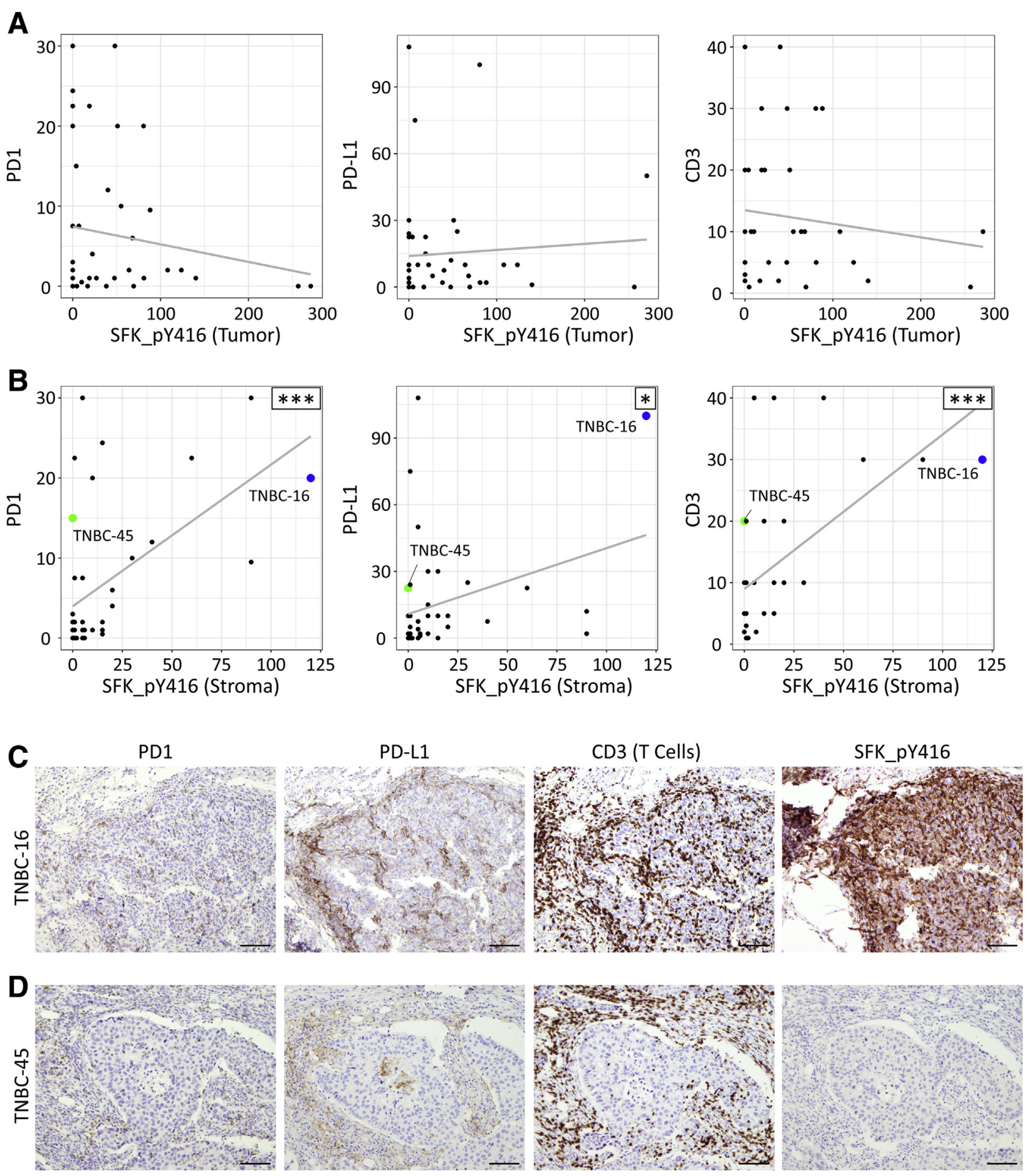

Figure 7 SFK is phosphorylated at Y416 in tumor-infiltrating lymphocytes in a subset of triple-negative breast cancer (TNBC). Scatterplots showing relationship between SFK_pY416 expression and immune proteins. A: Tumor SFK_pY416 does not correlate with PD1/PD-L1 or T-cell marker CD3. B: Lymphocyte SFK_pY416 positively correlates with all three markers. Axes represent immunohistochemical (IHC) staining overall score (Materials and Methods). Enlarged blue and green points represent samples depicted in C and D. C: Representative IHC staining of TNBC-16 tumor with $\mathrm{CD} 3^{+} / \mathrm{PD} 1^{+} / \mathrm{PD}-\mathrm{L} 1^{+}$immune infiltrate and SFK_pY416 expression in both lymphocytes and tumor cells. D: Representative IHC staining of TNBC-45 tumor with $\mathrm{CD}^{+} / \mathrm{PD}^{+} / \mathrm{PD}-\mathrm{L1}^{+}$immune infiltrate but no SFK_pY416 expression. ${ }^{*} P<0.05,{ }^{* *} P<0.001$ between the two variables (Pearson product moment correlation test). Scale bars $=100 \mu \mathrm{m}(\mathbf{C}$ and $\mathbf{D})$.

proteins (Figure 7, B-D). Photomicrographs of two tumors demonstrating the variation that can be observed in TIL SFK activation in TNBC are shown in Figure 7, C and D. Both tumors have abundant PD1, PD-L1, and
CD3 staining in TILs. TNBC-16 contains abundant intratumoral and stromal lymphocytes with active SFK (Figure 7C), whereas TNBC-45 contains almost no lymphocytes with active SFK (Figure 7D). 
Table 4 Correlation of Immune Protein Staining with SFK_pY416 in FFPE TNBC Tumors

\begin{tabular}{|c|c|c|c|c|}
\hline \multirow{2}{*}{$\begin{array}{l}\text { Immune } \\
\text { protein }\end{array}$} & \multicolumn{2}{|l|}{ Tumor SFK_pY416 } & \multicolumn{2}{|c|}{ Lymphocyte SFK_pY416 } \\
\hline & Correlation $(\mathrm{R})^{*}$ & FDR & Correlation $(\mathrm{R})^{*}$ & FDR \\
\hline CTLA-4 & 0.05 & & 0.66 & $5 \times 10^{-6}$ \\
\hline PD1 & -0.14 & & 0.52 & $4 \times 10^{-4}$ \\
\hline PD-L1 & 0.07 & & 0.32 & 0.036 \\
\hline TIL & -0.16 & & 0.43 & $4 \times 10^{-3}$ \\
\hline CD3 & -0.12 & & 0.59 & $6 \times 10^{-4}$ \\
\hline
\end{tabular}

${ }^{*}$ Correlation $(\mathrm{R})$ derived by Pearson product moment correlation test.

CTLA4, cytotoxic T-lymphocyte protein 4; FDR, false discovery rate; FFPE, formalin fixed, paraffin embedded; PD1, programmed cell death protein 1; PD-L1, programmed cell death 1 ligand 1; TIL, tumor-infiltrating lymphocyte; TNBC, triple-negative breast cancer.

In summary, IHC and Western blot analysis shows that SFK activation exists in a subset of TNBC tumors and is accompanied by phosphorylation of the SFK substrates CDCP1 and PKC $\delta$. Active SFK exists in a biphosphorylated form $\left(\mathrm{pY} 416^{+} / \mathrm{pY} 527^{+}\right)$and is seen more often in FOXA $^{-} /$vimentin $^{+}$TNBC. Finally, active SFK in TILs, but not tumor cells, correlates with the expression of immune response markers in a subset of TNBC tumors.

\section{Discussion}

TNBC is a heterogeneous aggressive breast cancer subtype that disproportionately affects young women, African American women, and women with a germline mutation in BRCA-1. Loss of tumor suppressor functions in TNBC is well described, but the signaling pathways that drive the high proliferation rate and metastatic efficiency of TNBC are less well understood. Our research groups and others have investigated an oncogenic signaling pathway in TNBC in which SFK activation and $\mathrm{PKC} \delta$ are coupled through a receptor-like oncoprotein-CDCP1. ${ }^{44,49,53,69}$ CDCP1 is highly expressed and associated with poor prognosis in TNBC. ${ }^{43}$ TNBC cell lines are susceptible to growth inhibition by dasatinib, an SFK and Abl kinase inhibitor, but dasatinib had limited activity when used as a single agent in TNBC patients with chemotherapy-resistant disease. ${ }^{16,70}$ These findings suggest that successful targeting of SFK in TNBC requires a better understanding of SFK activation states and its downstream pathways driving tumorigenesis. This report presents a biochemical analysis of SFK activation based on its phosphorylation state and phosphorylation of its downstream substrates CDCP1 and PKC $\delta$ in clinical samples of 56 TNBCs. The cohort was annotated with FOXA1 and vimentin expression data, determined by IHC, based on reports that FOXA1 is highly expressed in LAR$\mathrm{TNBC}^{3,7}$ and vimentin is highly expressed in basal-like and mesenchymal TNBC. ${ }^{57,58}$

To identify TNBC with active SFK by IHC, an antibody that recognizes multiple SFK isoforms with a phosphorylated tyrosine residue in their activation loop (SFK_pY416) was used. Phosphorylation of the activation loop is a general mechanism for activation of protein kinases, ${ }^{31,71}$ and has been shown to lock the SFK kinase domain in an active conformation. ${ }^{33}$ Expression of SFK_pY416 was detected in tumor cells in $41 \%$ of this TNBC cohort. To determine whether expression of SFK_pY416 is a valid indication of SFK activity in TNBC, IHC was performed for phosphorylated substrates of SFK. Indeed, expression of SFK_pY416 was highly associated with phosphorylation of known SFK substrates CDCP1 and PKC $\delta\left(P<10^{-4}\right)$ (Table 3). Immunohistochemical detection of SFK_pY416 has been used previously to characterize TNBC. ${ }^{60,72}$ In this study, the SFK_pY416 analysis was complemented with analysis of phosphorylation of two SFK substrates, which strengthened the conclusion that SFK_pY416 ${ }^{+}$samples have active SFK signaling in TNBC.

The strong correlation between expression of SFK_pY416 and CDCP1_pY734/pY743 in TNBC clinical samples supports the conclusion previously made in cancer cell lines that CDCP1 activates SFK by serving as a binding platform for SFK autophosphorylation, and that active SFK, in turn, phosphorylates CDCP1 at multiple sites at its Cterminus. ${ }^{41,45}$ The observation that SFK_pY416 is not detected immunohistochemically in the absence of CDCP1 phosphorylation further supports this signaling relationship. Multiple studies in cell lines and animal models have clearly identified CDCP1 and PKC $\delta$ as crucial downstream effectors of SFK that directly contribute to aggressive behavior of cancer cells. ${ }^{38,40,44,46,49,53,69}$ Our discovery that this pathway is active in clinical samples of TNBC builds on these studies and solidifies the rationale for targeting this pathway in TNBC. Because of the well-established role of SFK in solid tumor progression, ${ }^{73}$ efforts have been focused on small-molecule discovery for direct targeting of SFK. However, SFK inhibition as a monotherapy has so far shown minimal efficacy in treating solid tumors, including TNBC. ${ }^{70,74}$ Clinical trials of SFK inhibitors have also been hampered by drug toxicity and serious adverse effects. ${ }^{74}$ Targeting either CDCP1 or PKC $\delta$ directly may be a better therapeutic strategy because CDCP1 knockout mice are viable with no known pathology. ${ }^{75}$ Recently, several strategies for inhibiting CDCP1 and/or PKC $\delta$ have been developed: i) anti-CDCP1 blocking antibodies prevented tissue colonization and caused poly (ADP-ribose) polymerase 1 -mediated apoptosis in vivo in a mouse metastasis model $^{61}$; ii) a small molecule blocking the interaction between CDCP1 and PKC $\delta$ showed promising antitumor effects in mouse models of gastric cancer and pancreatic cancer $^{76}$; and iii) a CDCP1 blocking fragment that acts extracellularly inhibited CDCP1 dimerization and $\mathrm{PKC} \delta$ activation and decreased tumor progression and metastasis in two mouse models of TNBC. ${ }^{44,77}$ Thus, targeting CDCP1 or PKC $\delta$ directly to inhibit this protumorigenic arm of SFK signaling may prove to be an effective therapeutic strategy for a subset of TNBC patients.

Western blot analysis of SFK_pY416 ${ }^{+}$tumor samples demonstrated that they were also SFK_pY527 ${ }^{+}$. Analysis of 
TCPA data confirmed a correlation between SFK_pY416 ${ }^{+}$ and SFK_pY527 $7^{+}$in TNBC (Figure 2B) and other tumor types (data not shown). Immunoprecipitation confirmed that SFK molecules are biphosphorylated (Figure 4). Although phosphorylation at Y527 is generally known as a negative regulator of SFK activity, ${ }^{30}$ biphosphorylated SFK has been previously reported to exist and be active. Nika et $\mathrm{al}^{78}$ demonstrated that Jurkat cells and naive human $\mathrm{CD}^{+}{ }^{+} \mathrm{T}$ cells contain biphosphorylated Lck. Biochemical reconstitution studies using purified recombinant SFK and C-terminal Src kinase have shown that C-terminal Src kinase can phosphorylate SFK at Y527 after it is activated by autophosphorylation at Y416, and that this biphosphorylated enzyme remains active. ${ }^{79}$ In addition, concurrent phosphorylation of both sites has been observed in a noncanonical pathway of SFK activation stimulated by oxidative stress. ${ }^{80}$ Phosphorylation of SFK downstream substrates CDCP1 and PKC $\delta$ in samples with biphosphorylated SFK confirms that it is active in that state. It is not clear from our studies whether the phosphorylation of Y527 occurs concurrently with or subsequent to phosphorylation of Y416 during the activation of SFK. However, the observation that most FOXA1 ${ }^{-}$TNBCs are either biphosphorylated or lack phosphate at both sites suggests that these phosphorylation events are linked in some way.

Western blot analysis of SFK_pY416 ${ }^{-}$TNBC also yielded interesting results. Specifically, in SFK_pY416 ${ }^{-} /$ $\mathrm{FOXA1}^{+} \mathrm{TNBC}$, SFK is phosphorylated at Y527, whereas in SFK_pY416 ${ }^{-}$FOXA1 ${ }^{-}$TNBC, SFK is generally not phosphorylated at Y527. Phosphorylation of Y527 stabilizes an inactive conformation of pY416 ${ }^{-}$SFK, and dephosphorylation of Y527 produces an SFK isoform with a flexible tertiary structure that may toggle between active and inactive conformations. ${ }^{81}$ In fact, classic biochemical analysis of recombinant SFK Hck has shown that the kinase with unphosphorylated Y416 and even Y416F/A mutants are active in solution. ${ }^{82,83}$ Our data suggest that SFK_pY416 ${ }^{-}$is not active in TNBC toward CDCP1. This discrepancy suggests that the mechanisms regulating SFK activity in cellular systems are more complex than simple dephosphorylation of Y527 and phosphorylation of Y416. Dephosphorylation of Y527 also frees the SFK Src homology domain 2 to bind phosphotyrosine sites on other proteins, potentially increasing the local concentration of $\mathrm{pY} 416^{-} / \mathrm{pY}^{2} 7^{-}$isoforms, leading to transautophosphorylation of $\mathrm{Y} 416$ and activation. $\mathrm{FOXA}^{-}$tumors thus appear to carry an isoform of SFK that is poised for activation. The absence of phosphate at Y527 in FOXA1 ${ }^{-}$TNBC observed in this study suggests that the equilibrium between kinase and phosphatase activities that regulates the phosphorylation of Y527 is altered in FOXA1 ${ }^{-}$TNBC. However, the mechanism behind this phenomenon is unknown and warrants further investigation.

In silico analysis of the gene expression profiles of TNBC revealed a positive correlation between expression of SFK_pY416 and expression of immunomodulatory genes encoding PD1, PD-L1, CTLA-4, and PD-L2, among others. The IHC analysis reported herein suggests that this correlation is primarily due to SFK activation in TILs. Specifically, it was determined that SFK_pY416 is highly expressed by lymphocytes in a subset of TNBC with abundant TILs. This finding is of interest because, although the abundance of TILs in TNBC has been identified as both a prognostic and a predictive variable, ${ }^{84}$ research has begun to focus on the functional properties of TILs and tumorspecific factors that interact with TILs that influence the response of tumors to immunomodulatory therapies. ${ }^{85}$ Although it was initially considered that SFK activation in tumor cells might be associated with immune activation on the basis of our in silico observations, TCGA and TCPA data sets are not mapped to the multitude of tumor, connective tissue, and immune cell types in tumors. The use of an in situ method (immunohistochemistry) allowed deciphering an interesting correlation initially discovered in silico.

This study demonstrates the feasibility of Western blot analysis of proteins extracted from FFPE tissue to assess signaling pathway activity. Despite the extensive protein chemical modifications and denaturation associated with formalin fixation and paraffin embedding, protein antigens have been analyzed in FFPE tissue by IHC since the advent of antigen retrieval methods. ${ }^{86}$ The first successful application of shotgun proteomics to FFPE was reported in $2005 .^{87}$ Since then, several reports have indicated that the protein composition of tissue in FFPE material is equivalent to fresh tissue ${ }^{88,89}$ Complete solubilization of proteins in FFPE is not essential for successful bottom-up proteomic analysis because proteins are fragmented in this approach. $^{87,90,91}$ However, complete solubilization is essential for methods, such as Western blot analysis, in which intact proteins are analyzed according to their molecular weight. The solubilization procedure used in this study was validated by comparison of Western blot analyses of extracts prepared from fresh and cognate FFPE tissue samples (data not shown) and is similar to a solubilization procedure validated by mass spectroscopy. ${ }^{89}$ The buffer used to solubilize FFPE for Western blot analysis has $4 \%$ SDS and $100 \mathrm{mmol} / \mathrm{L}$ DTT. We found that optimal solubilization of proteins in FFPE tissue requires at least 10 $\mathrm{mmol} / \mathrm{L}$ DTT. In the presence of $10 \mathrm{mmol} / \mathrm{L}$ DTT, SDS levels as low as $1 \%$ showed no decrease in performance, facilitating downstream applications requiring a nondenaturing environment (such as immunoprecipitation). Other investigators have shown that high pressure improves the solubilization of proteins from FFPE. ${ }^{92}$ High-pressure systems for protein extraction were not used in this study because all of the proteins of interest could be detected with the method used; the utilization of high-pressure systems might be essential for protein extraction to detect other protein types. Western blot analyses should be ideal for characterizing proteins in FFPE that are expressed as variable molecular weight isoforms due to proteolysis, as shown 
herein for CDCP1, or isoforms arising from alternate mRNA splicing. The number of antibodies that are validated for use in Western blot analysis far exceeds the number of antibodies validated for use in paraffin IHC. The ability to evaluate protein expression in FFPE tissue by Western blot analysis expands the catalog of antibodies that can be used to study archived tissue.

This study analyzed single 3- or 4-mm punch biopsies of a selected group of TNBC resections. Patients who received neoadjuvant chemotherapy were largely excluded, and therefore older patients and smaller tumors are probably overrepresented in this cohort of TNBC. The most cellular areas of primary tumors were selected for analysis, generally near but not necessarily including the tumor-stroma interface. This approach was essential to our goal of analyzing individual tumor foci by Western blot analysis. This selection process may have resulted in overrepresentation or underrepresentation of some aspects of TNBC biology. The potential limitations of this approach are similar to those that have been considered potentially limiting for tissue microarray studies. ${ }^{93}$ The area of a 4-mm punch biopsy is $>40$ fold larger than the area of a standard $0.6-\mathrm{mm}$ tissue microarray core, but still represents a limited part of the tumor it came from. Bias introduced by examining punch biopsy samples rather than whole tumor sections may be particularly relevant to the study of tumor microenvironment. Herein, we analyzed only three immune checkpoint proteins, and they were scored manually from single marker IHC stains. An accurate assessment of the tumor immune landscape requires multiplexed imaging and sophisticated digital image analysis, as described by Giraldo et al. ${ }^{94}$ Another potential limitation of the current study is the use of resected tumors to evaluate phosphoprotein markers. Protein phosphorylation may fluctuate significantly during the period of ischemia that occurs during and after surgical resection. ${ }^{95,96}$ The stability of the phosphoprotein markers in our study was analyzed, and they were found to be generally stable (data not shown), but we recognize that analysis of more rapidly fixed TNBC tissue could reach different conclusions. Our observations regarding the phosphorylation and activity of SFK/CDCP1/PKC $\delta$ pathway were highly consistent but were based solely on tumor foci with activation of SFK in a high percentage of tumor cells. Samples with more focal activation of SFK were not analyzed by Western blot analysis in the current study.

In summary, this study provides evidence that SFK activation occurs in tumor cells as well as the microenvironment of TNBC, specifically in TILs. SFK activation in TNBC tumor cells is associated with phosphorylation of SFK substrates-CDCP1 and PKC $\delta$. SFK activation in TNBC was most often observed in FOXA1 ${ }^{-}$TNBC and was associated with phosphorylation of both Y416 and Y527 in SFK. The pattern of SFK phosphorylation was dependent on the tumor type as well as the SFK activation status: in FOXA1 $^{+}$TNBC, when Y416 is not phosphorylated, Y527 generally is phosphorylated (canonic inactive state); in FOXA1 ${ }^{-}$TNBC, Y416 and Y527 are generally not phosphorylated (poised activation state) or are both phosphorylated (noncanonic active state). These results generate novel insights into SFK activation in TNBC subtypes and strengthen the rationale behind targeting the SFK/ CDCP1/PKC $\delta$ signaling in a subset of TNBC patients.

\section{Acknowledgment}

We thank the Laser Spectroscopy Labs (University of California, Irvine) for use of facilities.

\section{Author Contributions}

F.S.H., L.J.N., H.J.W., and O.V.R. designed the study; L.J.N., F.S.H., N.B.D., H.J.W., and K.D.N. performed the experiments and acquired the data; L.J.N., F.S.H., and O.V.R. analyzed the data; L.J.N., F.S.H., and O.V.R. wrote and reviewed the manuscript.

\section{Supplemental Data}

Supplemental material for this article can be found at https://doi.org/10.1016/j.ajpath.2019.10.017.

\section{References}

1. Foulkes WD, Smith IE, Reis-Filho JS: Triple-negative breast cancer. N Engl J Med 2010, 363:1938-1948

2. Carey L, Winer E, Viale G, Cameron D, Gianni L: Triple-negative breast cancer: disease entity or title of convenience? Nat Rev Clin Oncol 2010, 7:683-692

3. Doane AS, Danso M, Lal P, Donaton M, Zhang L, Hudis C, Gerald WL: An estrogen receptor-negative breast cancer subset characterized by a hormonally regulated transcriptional program and response to androgen. Oncogene 2006, 25:3994-4008

4. Farmer P, Bonnefoi H, Becette V, Tubiana-Hulin M, Fumoleau P, Larsimont D, MacGrogan G, Bergh J, Cameron D, Goldstein D, Duss S, Nicoulaz A-L, Brisken C, Fiche M, Delorenzi M, Iggo R: Identification of molecular apocrine breast tumours by microarray analysis. Oncogene 2005, 24:4660-4671

5. Robinson JLL, MacArthur S, Ross-Innes CS, Tilley WD, Neal DE, Mills IG, Carroll JS: Androgen receptor driven transcription in molecular apocrine breast cancer is mediated by FoxA1. EMBO J 2011, 30:3019-3027

6. Augello MA, Hickey TE, Knudsen KE: FOXA1: master of steroid receptor function in cancer. EMBO J 2011, 30:3885-3894

7. Lehmann BD, Bauer JA, Chen X, Sanders ME, Chakravarthy AB, Shyr Y, Pietenpol JA: Identification of human triple-negative breast cancer subtypes and preclinical models for selection of targeted therapies. J Clin Invest 2011, 121:2750-2767

8. Lehmann BD, Jovanović B, Chen X, Estrada MV, Johnson KN, Shyr Y, Moses HL, Sanders ME, Pietenpol JA: Refinement of triplenegative breast cancer molecular subtypes: implications for neoadjuvant chemotherapy selection. PLoS One 2016, 11:e0157368

9. Burstein MD, Tsimelzon A, Poage GM, Covington KR, Contreras A, Fuqua SAW, Savage MI, Osborne CK, Hilsenbeck SG, Chang JC, Mills GB, Lau CC, Brown PH: Comprehensive genomic analysis 
identifies novel subtypes and targets of triple-negative breast cancer. Clin Cancer Res 2015, 21:1688-1698

10. Bareche $\mathrm{Y}$, Venet D, Ignatiadis M, Aftimos P, Piccart M, Rothe F, Sotiriou C: Unravelling triple-negative breast cancer molecular heterogeneity using an integrative multiomic analysis. Ann Oncol 2018, 29:895-902

11. Jézéquel $\mathrm{P}$, Loussouarn $\mathrm{D}$, Guérin-Charbonnel $\mathrm{C}$, Campion L, Vanier A, Gouraud W, Lasla H, Guette C, Valo I, Verrièle V, Campone M: Gene-expression molecular subtyping of triple-negative breast cancer tumours: importance of immune response. Breast Cancer Res 2015, 17:43

12. Hunter T: Discovering the first tyrosine kinase. Proc Natl Acad Sci U S A 2015, 112:7877-7882

13. Irby RB, Yeatman TJ: Role of Src expression and activation in human cancer. Oncogene 2000, 19:5636-5642

14. Summy JM, Gallick GE: Src family kinases in tumor progression and metastasis. Cancer Metastasis Rev 2003, 22:337-358

15. Yeatman TJ: A renaissance for SRC. Nat Rev Cancer 2004, 4: 470-480

16. Finn RS: Targeting Src in breast cancer. Ann Oncol 2008, 19: $1379-1386$

17. Wheeler DL, Iida M, Dunn EF: The role of Src in solid tumors. Oncologist 2009, 14:667-678

18. Elsberger B: Translational evidence on the role of Src kinase and activated Src kinase in invasive breast cancer. Crit Rev Oncol Hematol 2014, 89:343-351

19. Verbeek BS, Vroom TM, Adriaansen-Slot SS, Ottenhoff-Kalff AE, Geertzema JGN, Hennipman A, Rijksen G: c-Src protein expression is increased in human breast cancer: an immunohistochemical and biochemical analysis. J Pathol 1996, 180:383-388

20. Rosen N, Bolen JB, Schwartz AM, Cohen P, DeSeau V, Israel MA: Analysis of pp60c-src protein kinase activity in human tumor cell lines and tissues. J Biol Chem 1986, 261:13754-13759

21. Bolen JB, Veillette A, Schwartz AM, DeSeau V, Rosen N: Activation of pp60c-src protein kinase activity in human colon carcinoma. Proc Natl Acad Sci U S A 1987, 84:2251-2255

22. Talamonti MS, Roh MS, Curley SA, Gallick GE: Increase in activity and level of pp60c-src in progressive stages of human colorectal cancer. J Clin Invest 1993, 91:53-60

23. Muthuswamy SK, Siegel PM, Dankort DL, Webster MA, Muller WJ Mammary tumors expressing the neu proto-oncogene possess elevated c-Src tyrosine kinase activity. Mol Cell. Biol 1994, 14: 735-743

24. Choi Y-L, Bocanegra M, Kwon MJ, Shin YK, Nam SJ, Yang J-H, Kao J, Godwin AK, Pollack JR: LYN is a mediator of epithelialmesenchymal transition and a target of dasatinib in breast cancer. Cancer Res 2010, 70:2296-2306

25. Elsberger B, Fullerton R, Zino S, Jordan F, Mitchell TJ, Brunton VG, Mallon EA, Shiels PG, Edwards J: Breast cancer patients' clinical outcome measures are associated with Src kinase family member expression. Br J Cancer 2010, 103:899-909

26. Tornillo G, Knowlson C, Kendrick H, Cooke J, Mirza H, Aurrekoetxea-Rodríguez I, Vivanco MdM, Buckley NE, Grigoriadis A, Smalley MJ: Dual mechanisms of LYN kinase dysregulation drive aggressive behavior in breast cancer cells. Cell Rep 2018, 25: 3674-3692.e10

27. Curtis C, Shah SP, Chin S-F, Turashvili G, Rueda OM, Dunning MJ, Speed D, Lynch AG, Samarajiwa S, Yuan Y, Gräf S, Ha G, Haffari G, Bashashati A, Russell R, McKinney S, Group M, Langerød A, Green A, Provenzano E, Wishart G, Pinder S, Watson P, Markowetz F, Murphy L, Ellis I, Purushotham A, Børresen-Dale A-L, Brenton JD, Tavaré S, Caldas C, Aparicio S: The genomic and transcriptomic architecture of 2,000 breast tumours reveals novel subgroups. Nature 2012, 486:346-352

28. Cancer Genome Atlas Network: Comprehensive molecular portraits of human breast tumours. Nature 2012, 490:61-70
29. Bailey MH, Tokheim C, Porta-Pardo E, Sengupta S, Bertrand D, Weerasinghe A, et al: Comprehensive characterization of cancer driver genes and mutations. Cell 2018, 173:371-385.e18

30. Roskoski R: Src protein-tyrosine kinase structure and regulation. Biochem Biophys Res Commun 2004, 324:1155-1164

31. Taylor SS, Keshwani MM, Steichen JM, Kornev AP: Evolution of the eukaryotic protein kinases as dynamic molecular switches. Philos Trans R Soc Lond B Biol Sci 2012, 367:2517-2528

32. Okada M: Regulation of the SRC family kinases by Csk. Int J Biol Sci 2012, 8:1385-1397

33. Meng Y, Roux B: Locking the active conformation of c-Src kinase through the phosphorylation of the activation loop. J Mol Biol 2014, 426:423-435

34. Bromann PA, Korkaya H, Courtneidge SA: The interplay between Src family kinases and receptor tyrosine kinases. Oncogene 2004, 23 : 7957-7968

35. Thomas SM, Brugge JS: Cellular functions regulated by Src family kinases. Annu Rev Cell Dev Biol 1997, 13:513-609

36. Brown MT, Cooper JA: Regulation, substrates and functions of src. Biochim Biophys Acta 1996, 1287:121-149

37. Mader CC, Oser M, Magalhaes MAO, Bravo-Cordero JJ, Condeelis J, Koleske AJ, Gil-Henn H: An EGFR-Src-Arg-cortactin pathway mediates functional maturation of invadopodia and breast cancer cell invasion. Cancer Res 2011, 71: $1730-1741$

38. Kollmorgen G, Bossenmaier B, Niederfellner G, Häring H-U, Lammers R: Structural requirements for cub domain containing protein 1 (CDCP1) and Src dependent cell transformation. PLoS One 2012, 7:e53050

39. Brown TA, Yang TM, Zaitsevskaia T, Xia Y, Dunn CA, Sigle RO, Knudsen B, Carter WG: Adhesion or plasmin regulates tyrosine phosphorylation of a novel membrane glycoprotein p80/gp140/CUB domain-containing protein 1 in epithelia. J Biol Chem 2004, 279: $14772-14783$

40. Liu H, Ong S-E, Badu-Nkansah K, Schindler J, White FM, Hynes RO: CUB-domain-containing protein 1 (CDCP1) activates Src to promote melanoma metastasis. Proc Natl Acad Sci U S A 2011, 108:1379-1384

41. Benes CH, Wu N, Elia AEH, Dharia T, Cantley LC, Soltoff SP: The C2 domain of PKCdelta is a phosphotyrosine binding domain. Cell 2005, 121:271-280

42. Uekita T, Sakai R: Roles of CUB domain-containing protein 1 signaling in cancer invasion and metastasis. Cancer Sci 2011, 102: 1943-1948

43. Turdo F, Bianchi F, Gasparini P, Sandri M, Sasso M, De Cecco L, Forte L, Casalini P, Aiello P, Sfondrini L, Agresti R, Carcangiu ML, Plantamura I, Sozzi G, Tagliabue E, Campiglio M: CDCP1 is a novel marker of the most aggressive human triple-negative breast cancers. Oncotarget 2016, 7:69649-69665

44. Wright HJ, Arulmoli J, Motazedi M, Nelson LJ, Heinemann FS, Flanagan LA, Razorenova OV: CDCP1 cleavage is necessary for homodimerization-induced migration of triple-negative breast cancer. Oncogene 2016, 35:4762-4772

45. Bhatt AS, Erdjument-Bromage H, Tempst P, Craik CS, Moasser MM: Adhesion signaling by a novel mitotic substrate of src kinases. Oncogene 2005, 24:5333-5343

46. Leroy C, Shen Q, Strande V, Meyer R, McLaughlin ME, Lezan E, Bentires-Alj M, Voshol H, Bonenfant D, Alex Gaither L: CUBdomain-containing protein 1 overexpression in solid cancers promotes cancer cell growth by activating Src family kinases. Oncogene 2015, 34:5593-5598

47. Wong CH, Baehner FL, Spassov DS, Ahuja D, Wang D, Hann B, Blair J, Shokat K, Welm AL, Moasser MM: Phosphorylation of the SRC epithelial substrate Trask is tightly regulated in normal epithelia but widespread in many human epithelial cancers. Clin Cancer Res 2009, 15:2311-2322 
48. Benes C, Soltoff SP: Modulation of PKCdelta tyrosine phosphorylation and activity in salivary and PC-12 cells by Src kinases. Am J Physiol Cell Physiol 2001, 280:C1498-C1510

49. Razorenova OV, Finger EC, Colavitti R, Chernikova SB, Boiko AD, Chan CKF, Krieg A, Bedogni B, LaGory E, Weissman IL, BroomePowell M, Giaccia AJ: VHL loss in renal cell carcinoma leads to upregulation of CUB domain-containing protein 1 to stimulate PKC \{delta\}-driven migration. Proc Natl Acad Sci U S A 2011, 108: 1931-1936

50. Isakov N: Protein kinase $\mathrm{C}$ (PKC) isoforms in cancer, tumor promotion and tumor suppression. Semin Cancer Biol 2018, 48:36-52

51. Allen-Petersen BL, Carter CJ, Ohm AM, Reyland ME: Protein kinase $\mathrm{C} \delta$ is required for ErbB2-driven mammary gland tumorigenesis and negatively correlates with prognosis in human breast cancer. Oncogene 2014, 33:1306-1315

52. Garg R, Benedetti LG, Abera MB, Wang H, Abba M, Kazanietz MG: Protein kinase $\mathrm{C}$ and cancer: what we know and what we do not. Oncogene 2014, 33:5225-5237

53. Benes C, Poulogiannis G, Cantley L, Soltoff S: The SRC-associated protein CUB domain-containing protein-1 regulates adhesion and motility. Oncogene 2012, 31:653-663

54. Wiśniewski JR, Gaugaz FZ: Fast and sensitive total protein and peptide assays for proteomic analysis. Anal Chem 2015, 87: 4110-4116

55. Benjamini Y, Hochberg Y: Controlling the false discovery rate: a practical and powerful approach to multiple testing. J R Stat Soc Ser B Methodol 1995, 57:289-300

56. Hennessy BT, Gonzalez-Angulo A-M, Stemke-Hale K, Gilcrease MZ, Krishnamurthy S, Lee J-S, Fridlyand J, Sahin A, Agarwal R, Joy C, Liu W, Stivers D, Baggerly K, Carey M, Lluch A, Monteagudo $\mathrm{C}$, He X, Weigman $\mathrm{V}$, Fan $\mathrm{C}$, Palazzo J, Hortobagyi GN, Nolden LK, Wang NJ, Valero V, Gray JW, Perou CM, Mills GB: Characterization of a naturally occurring breast cancer subset enriched in epithelial-to-mesenchymal transition and stem cell characteristics. Cancer Res 2009, 69:4116-4124

57. Sarrió D, Rodriguez-Pinilla SM, Hardisson D, Cano A, MorenoBueno G, Palacios J: Epithelial-mesenchymal transition in breast cancer relates to the basal-like phenotype. Cancer Res 2008, 68:989-997

58. Prat A, Parker JS, Karginova O, Fan C, Livasy C, Herschkowitz JI, He X, Perou CM: Phenotypic and molecular characterization of the claudin-low intrinsic subtype of breast cancer. Breast Cancer Res 2010, 12:R68

59. Cimino-Mathews A, Subhawong AP, Elwood H, Warzecha HN, Sharma R, Park BH, Taube JM, Illei PB, Argani P: Neural crest transcription factor Sox 10 is preferentially expressed in triple-negative and metaplastic breast carcinomas. Hum Pathol 2013, 44:959-965

60. Anbalagan M, Moroz K, Ali A, Carrier L, Glodowski S, Rowan BG: Subcellular localization of total and activated Src kinase in African American and Caucasian breast cancer. PLoS One 2012, 7:e33017

61. Casar B, He Y, Iconomou M, Hooper JD, Quigley JP, Deryugina EI: Blocking of CDCP1 cleavage in vivo prevents Akt-dependent survival and inhibits metastatic colonization through PARP1-mediated apoptosis of cancer cells. Oncogene 2012, 31:3924-3938

62. Li J, Lu Y, Akbani R, Ju Z, Roebuck PL, Liu W, Yang J-Y, Broom BM, Verhaak RGW, Kane DW, Wakefield C, Weinstein JN, Mills GB, Liang H: TCPA: a resource for cancer functional proteomics data. Nat Methods 2013, 10:1046-1047

63. Sausgruber N, Coissieux M-M, Britschgi A, Wyckoff J, Aceto N, Leroy C, Stadler MB, Voshol H, Bonenfant D, Bentires-Alj M: Tyrosine phosphatase SHP2 increases cell motility in triple-negative breast cancer through the activation of SRC-family kinases. Oncogene 2015, 34:2272-2278

64. Laird AD, Li G, Moss KG, Blake RA, Broome MA, Cherrington JM, Mendel DB: Src family kinase activity is required for signal tranducer and activator of transcription 3 and focal adhesion kinase phosphorylation and vascular endothelial growth factor signaling in vivo and for anchorage-dependent and -independent growth of human tumor cells. Mol Cancer Ther 2003, 2:461-469

65. Zamoyska R, Basson A, Filby A, Legname G, Lovatt M, Seddon B: The influence of the src-family kinases, Lck and Fyn, on T cell differentiation, survival and activation. Immunol Rev 2003, 191: $107-118$

66. Palacios EH, Weiss A: Function of the Src-family kinases, Lck and Fyn, in T-cell development and activation. Oncogene 2004, 23: 7990-8000

67. Szklarczyk D, Morris JH, Cook H, Kuhn M, Wyder S, Simonovic M, Santos A, Doncheva NT, Roth A, Bork P, Jensen LJ, von Mering C: The STRING database in 2017: quality-controlled protein-protein association networks, made broadly accessible. Nucleic Acids Res 2017, 45:D362-D368

68. Voorwerk L, Kat M, Kok M: Towards predictive biomarkers for immunotherapy response in breast cancer patients. Breast Cancer Manag 2018, 7:BMT05

69. Uekita T, Jia L, Narisawa-Saito M, Yokota J, Kiyono T, Sakai R: CUB domain-containing protein 1 is a novel regulator of anoikis resistance in lung adenocarcinoma. Mol Cell Biol 2007, 27: 7649-7660

70. Finn RS, Bengala C, Ibrahim N, Roché H, Sparano J, Strauss LC, Fairchild J, Sy O, Goldstein LJ: Dasatinib as a single agent in triplenegative breast cancer: results of an Open-Label Phase 2 Study. Clin Cancer Res 2011, 17:6905-6913

71. Adams JA: Activation loop phosphorylation and catalysis in protein kinases: is there functional evidence for the autoinhibitor model? Biochemistry 2003, 42:601-607

72. Elsberger B, Tan BA, Mitchell TJ, Brown SBF, Mallon EA, Tovey SM, Cooke TG, Brunton VG, Edwards J: Is expression or activation of Src kinase associated with cancer-specific survival in ER-, PR- and HER2-negative breast cancer patients? Am J Pathol 2009, 175:1389-1397

73. Aleshin A, Finn RS: SRC: a century of science brought to the clinic. Neoplasia 2010, 12:599-607

74. Woodcock VK, Clive S, Wilson RH, Coyle VM, Stratford MRL, Folkes LK, Eastell R, Barton C, Jones P, Kazmi-Stokes S, Turner H, Halford S, Harris AL, Middleton MR: A first-in-human phase I study to determine the maximum tolerated dose of the oral Src/ABL inhibitor AZD0424. Br J Cancer 2018, 118:770-776

75. Spassov DS, Wong CH, Wong SY, Reiter JF, Moasser MM: Trask loss enhances tumorigenic growth by liberating integrin signaling and growth factor receptor cross-talk in unanchored cells. Cancer Res 2013, 73:1168-1179

76. Nakashima K, Uekita T, Yano S, Kikuchi J, Nakanishi R, Sakamoto N, Fukumoto K, Nomoto A, Kawamoto K, Shibahara T, Yamaguchi H, Sakai R: Novel small molecule inhibiting CDCP1PKC $\delta$ pathway reduces tumor metastasis and proliferation. Cancer Sci 2017, 108:1049-1057

77. Wright HJ, Hou J, Xu B, Cortez M, Potma EO, Tromberg BJ, Razorenova OV: CDCP1 drives triple-negative breast cancer metastasis through reduction of lipid-droplet abundance and stimulation of fatty acid oxidation. Proc Natl Acad Sci U S A 2017, 114: E6556-E6565

78. Nika K, Soldani C, Salek M, Paster W, Gray A, Etzensperger R, Fugger L, Polzella P, Cerundolo V, Dushek O, Höfer T, Viola A, Acuto O: Constitutively active lck kinase in $\mathrm{T}$ cells drives antigen receptor signal transduction. Immunity 2010, 32:766-777

79. Sun G, Sharma AK, Budde RJ: Autophosphorylation of Src and Yes blocks their inactivation by Csk phosphorylation. Oncogene 1998, 17:1587-1595

80. Zhang H, Davies KJA, Forman HJ: TGFß1 rapidly activates Src through a non-canonical redox signaling mechanism. Arch Biochem Biophys 2015, 568:1-7

81. Meng Y, Pond MP, Roux B: Tyrosine kinase activation and conformational flexibility: lessons from Src-family tyrosine kinases. Acc Chem Res 2017, 50:1193-1201 
82. Moarefi I, LaFevre-Bernt M, Sicheri F, Huse M, Lee CH, Kuriyan J, Miller WT: Activation of the Src-family tyrosine kinase Hck by SH3 domain displacement. Nature 1997, 385:650-653

83. Porter M, Schindler T, Kuriyan J, Miller WT: Reciprocal regulation of Hck activity by phosphorylation of Tyr527 and Tyr416: effect of introducing a high affinity intramolecular SH2 ligand. J Biol Chem 2000, 275:2721-2726

84. Loi S, Drubay D, Adams S, Pruneri G, Francis PA, Lacroix-Triki M, Joensuu H, Dieci MV, Badve S, Demaria S, Gray R, Munzone E, Lemonnier J, Sotiriou C, Piccart MJ, Kellokumpu-Lehtinen P-L, Vingiani A, Gray K, Andre F, Denkert C, Salgado R, Michiels S: Tumor-infiltrating lymphocytes and prognosis: a pooled individual patient analysis of early-stage triple-negative breast cancers. J Clin Oncol 2019, 37:559-569

85. Chen DS, Mellman I: Elements of cancer immunity and the cancer-immune set point. Nature 2017, 541:321-330

86. Shi SR, Key ME, Kalra KL: Antigen retrieval in formalin-fixed, paraffin-embedded tissues: an enhancement method for immunohistochemical staining based on microwave oven heating of tissue sections. J Histochem Cytochem 1991, 39:741-748

87. Hood BL, Darfler MM, Guiel TG, Furusato B, Lucas DA, Ringeisen BR, Sesterhenn IA, Conrads TP, Veenstra TD, Krizman DB: Proteomic analysis of formalin-fixed prostate cancer tissue. Mol Cell Proteomics 2005, 4:1741-1753

88. Sprung RW, Brock JWC, Tanksley JP, Li M, Washington MK, Slebos RJC, Liebler DC: Equivalence of protein inventories obtained from formalin-fixed paraffin-embedded and frozen tissue in multidimensional liquid chromatography-tandem mass spectrometry shotgun proteomic analysis. Mol Cell Proteomics 2009, 8:1988-1998

89. Ostasiewicz P, Zielinska DF, Mann M, Wiśniewski JR: Proteome, phosphoproteome, and $\mathrm{N}$-glycoproteome are quantitatively preserved in formalin-fixed paraffin-embedded tissue and analyzable by high-resolution mass spectrometry. J Proteome Res 2010, 9: $3688-3700$

90. Shi S-R, Taylor CR, Fowler CB, Mason JT: Complete solubilization of formalin-fixed, paraffin-embedded tissue may improve proteomic studies. Proteomics Clin Appl 2013, 7:264-272

91. Pedersen MH, Hood BL, Beck HC, Conrads TP, Ditzel HJ, Leth-Larsen R: Downregulation of antigen presentationassociated pathway proteins is linked to poor outcome in triple-negative breast cancer patient tumors. Oncoimmunology 2017, 6:e1305531

92. Fowler CB, Chesnick IE, Moore CD, O'Leary TJ, Mason JT: Elevated pressure improves the extraction and identification of proteins recovered from formalin-fixed, paraffin-embedded tissue surrogates. PLoS One 2010, 5:e14253

93. Giltnane JM, Rimm DL: Technology insight: identification of biomarkers with tissue microarray technology. Nat Clin Pract Oncol 2004, 1:104-111

94. Giraldo NA, Nguyen P, Engle EL, Kaunitz GJ, Cottrell TR, Berry S, Green B, Soni A, Cuda JD, Stein JE, Sunshine JC, Succaria F, Xu H, Ogurtsova A, Danilova L, Church CD, Miller NJ, Fling S, Lundgren L, Ramchurren N, Yearley JH, Lipson EJ, Cheever M, Anders RA, Nghiem PT, Topalian SL, Taube JM: Multidimensional, quantitative assessment of PD-1/PD-L1 expression in patients with Merkel cell carcinoma and association with response to pembrolizumab. J Immunother Cancer 2018, 6:99

95. Baker AF, Dragovich T, Ihle NT, Williams R, Fenoglio-Preiser C, Powis G: Stability of phosphoprotein as a biological marker of tumor signaling. Clin Cancer Res 2005, 11:4338-4340

96. Gündisch S, Annaratone L, Beese C, Drecol E, Marchiò C, Quaglino E, Sapino A, Becker K-F, Bussolati G: Critical roles of specimen type and temperature before and during fixation in the detection of phosphoproteins in breast cancer tissues. Lab Invest 2015, 95:561-571 